\title{
A COMPARISON OF THE CAPITAL COSTS OF LIGHT WATER REACTOR AND LIQUID METAL FAST BREEDER REACTOR POWER PLANTS
}

PREPARED FOR THE U. S. ARMS CONTROL AND DISARMAMENT AGENCY

WILLIAM E. MOOZ, SIDNEY SIEGEL

\author{
R-2441-ACDA
}

FEBRUARY 1979 


\section{DISCLAIMER}

This report was prepared as an account of work sponsored by an agency of the United States Government. Neither the United States Government nor any agency Thereof, nor any of their employees, makes any warranty, express or implied, or assumes any legal liability or responsibility for the accuracy, completeness, or usefulness of any information, apparatus, product, or process disclosed, or represents that its use would not infringe privately owned rights. Reference herein to any specific commercial product, process, or service by trade name, trademark, manufacturer, or otherwise does not necessarily constitute or imply its endorsement, recommendation, or favoring by the United States Government or any agency thereof. The views and opinions of authors expressed herein do not necessarily state or reflect those of the United States Government or any agency thereof. 


\section{DISCLAIMER}

Portions of this document may be illegible in electronic image products. Images are produced from the best available original document. 


\section{A COMPARISON OF THE CAPITAL COSTS OF LIGHT WATER REACTOR AND LIQUID METAL FAST BREEDER REACTOR POWER PLANTS}

PREPARED FOR THE U. S. ARMS CONTROL AND DISARMAMENT AGENCY

WILLAM E. MOOZ, SIDNEY SIEGEL

R-2441-ACDA

FEBRUARY 1979 

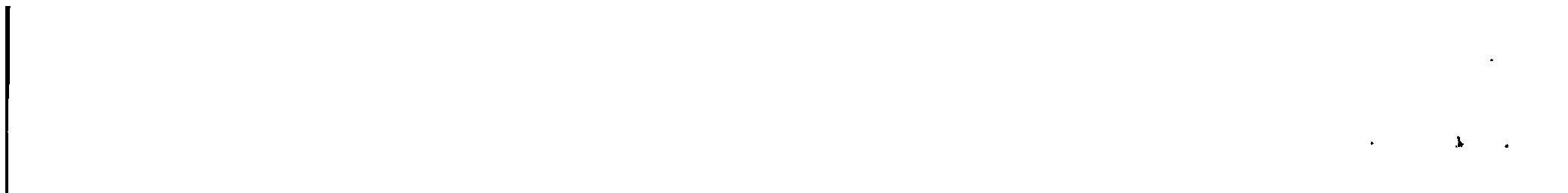

.

(1)

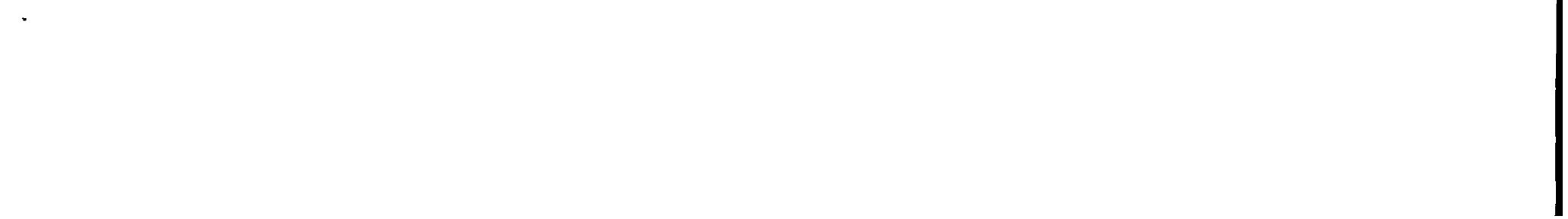




\section{PREFACE}

The objective of this study, sponsored by the Arms Control and Disarmament Agency (ACDA), was to develop plausible estimates of the relative capital costs of liquid metal fast breeder reactor (LMFBR) and light water reactor (LWR) power plants that might be built early in the next century. Past experience with predictions and actual trends of LWR plant costs indicates that this task is fraught with formidable obstacles.

Almost 60 LWR power plants have been constructed in the United States over the past 20 years. Extensive information is available about these plants and their capital costs. Even with this store of data, however, it is difficult to project capital costs as few as five years into the future. Plants using existing standardized designs for the nuclear steam supply systems and the rest of the plant ("balance of plant") can be built for costs that can be confidently estimated, in constant dollars. What is difficult to estimate is the cost of the plants that wizl be built, modified as they may have to be by social and political requirements, with construction schedules set as much by social as by industrial forces.

Projecting nuclear power plant capital costs into the next century thus becomes a subjective process, with wide-ranging results. For the LWR, there is at least the 20-year/60-odd plant data base with which to begin. For the LMFBR, there are no commercial plants in the United States providing a cost history from which cost projections can be made, only the recently completed Fast Test Reactor (FTR) and the stillongoing design and limited component manufacture of the Clinch River Breeder Reactor (CRBR), plus the results of conceptual design and cost studies.

The present study began with an analysis of cost estimates by three firms experienced in LMFBR design, all participants in the FTR and CRBR projects, and all involved in the design studies of the prototype large breeder reactor (PLBR). With these data, the authors estimated a "current" cost for a mature LMFBR. They then selected two 
scenarios for the deployment of nuclear power during the next 40 years. In one, the social and political environment vigorously encourages nuclear power; in the other, nuclear deployment is held to a modest level by continued social and political concerns about current and future perceived hazards. In the latter scenario, the inherent costs of nuclear plants are increased by additional items and procedures for which society is assumed to be willing to allocate its resources.

These scenarios illustrate the major uncertainties. Results are given in the form of sets of capital costs and cost ratios representative of each scenario. Depending on which scenario a user of this study chooses, a plausible LMFBR/LWR cost ratio can be found. The scenarios also help to identify where the real uncertainties lie and to quantify the likely effects of important variables, e.g., construction time. By so doing, estimates by others may be considered in a proper context, and consistencies or contradictions better understood. The results of this study constitute one input into an overall study designed to estimate the relative costs of generating electricity by LWRs and LMFBRs. Such cost calculations require estimates of fuel cycle costs, operating and maintenance costs, and capacity factors, in addition to capital cost estimates. These estimates, to be provided by other ACDA contractors, will be integrated into a final picture of relative electricity costs by Pan Heuristics, Inc.

Sidney Siegel is a consultant to The Rand Corporation. 
Recent studies by Atomics International, General Electric, and Westinghouse * yielded capital cost estimates for a "fifth of a kind" LMFBR. After adjusting these estimates for plant size and converting them to 1978 dollars, they ranged from $\$ 1043$ to $\$ 1495$ per kWe, excluding interest during construction (IDC). These cost estimates were compared in this study with a LWR estimated by GE to cost $\$ 900$ per $\mathrm{kWe}$, also excluding IDC.

Projecting these costs far into the future entails great uncertainty. An examination of the capital costs of LWRs built in the United States shows that they have increased steadily, in terms of constant dollars, at a rate so great that one could question their competitiveness or economic viability a short time in the future, if the trend were to continue. The data available give no clue as to how or when these cost increases might cease, and without such information, projections of LWR capital costs must rely on assumptions about future conditions that affect these costs. There is no comparable data base for the LMFBR. Instead we have the study estimates from Atomics International, General Electric, and Westinghouse. Projecting these estimates can only be done by examining the LWR experience and postulating how future events might affect costs.

The actual costs of both the LWR and the LMFBR in the early 2000s will depend strongly on the environment for nuclear power at that time. Since we cannot know what that future environment will be like, this study postulated two scenarios that might be representative of two future situations. These scenarios do not represent extremes in points of view; they are simply two different climates affecting nuclear costs. In the first, a vigorous nuclear industry is postulated, numerous LWR plants are being built, and LWR capital costs depart markedly from

\footnotetext{
*Each of these companies was teamed with an architect engineering firm. Atomics International was paired with Burns and Roe, General Electric with Bechte1, and Westinghouse with Stone and Webster. Al1 references in this report to the companies mean the teams of the companies and the architect engineering firms.
} 
current1y observed trends, leveling off at about $\$ 700$ per kWe, excluding IDC, and about $\$ 860$ per kWe with IDC included. The commercial deployment of LFMBRs begins in 2002, and the number of plants increases in the same fashion as in the early deployment of the LWRs. When the "fifth of kind" LMFBR reaches commercial operation, the LMFBR/LWR cost ratio is about 1.4. Costs decrease thereafter, and eventually become asymptotic at a ratio of about 1.2, assuming equal construction times for both types of plant.

The second scenario postulates a generally unfavorable environment for nuclear power, with continued public opposition and regulatory uncertainties regarding the LMFBR. In this scenario, the nuclear industry is weak, only a few LWRs are being built, and LWR costs are higher than in the first scenario. The LMFBR encounters new safety, safeguards, and political or institutional problems which drive up its costs. The LMFBR/LWR cost ratio is initially about 1.5 , , but increases thereafter due to rising LMFBR but relatively stable LWR costs. The ratio eventually reaches 1.75 , assuming equal construction times. If the LMFBR construction schedule were 25 percent greater than for an LWR, the cost ratio would be 1.9 .

These two scenarios do not necessarily represent upper and lower bounds on future capital costs of these nuclear systems. Technological improvements in LMFBR designs and operating conditions could lower LMFBR per $k$ We costs below those estimated in the favorable case at some time beyond the horizon of this study. Conversely, unforeseen technical problems and regulatory requirements could result in LMFBR capital costs exceeding those estimated here. The issue of LMFBR costs under these latter circumstances could well be moot, since deployment of the system would be unlikely.

No significant effect on the costs or cost ratio could be associated with a delay, say of 10 years, in the commercial deployment of the LMFBR.

${ }^{*}$ The initial cost ratio obtained from the raw GE-Bechtel estimates was 1.64 . 
The principal factors that affect future capital cost ratios between the LMFBR and the LWR are

- The initial cost ratio that is assumed for the "1977" design plants.

- Assumptions about changes in scope resulting from the social, political, and regulatory climate.

- Differential construction times for the two types of plant.

The cost ratios are relatively unaffected by the LMFBR deployment schedule and cost learning effects, differential scaling effects, and the LMFBR introduction date. 


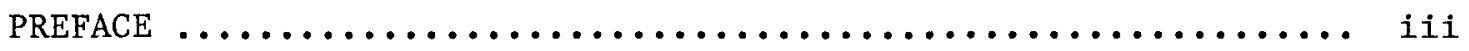

SUMMARY $\ldots \ldots \ldots \ldots \ldots \ldots \ldots \ldots \ldots \ldots \ldots \ldots \ldots \ldots \ldots \ldots \ldots \ldots$

Section

I. INTRODUCTION $\ldots \ldots \ldots \ldots \ldots \ldots \ldots \ldots \ldots \ldots \ldots \ldots \ldots \ldots \ldots \ldots$

II. CAPITAL COSTS FOR LMFBR POWER PLANTS .............. 5

Estimates from the Reactor Manufacturers ............ 6

Adjustments to Estimates ..................... 8

III. ESTIMATES OF LWR COSTS ...................... 11

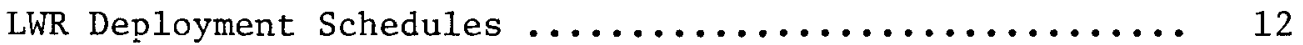

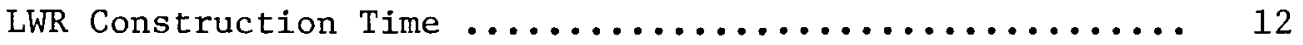

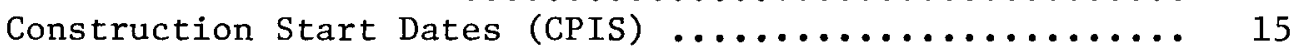

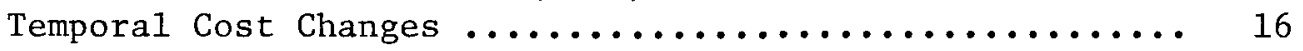

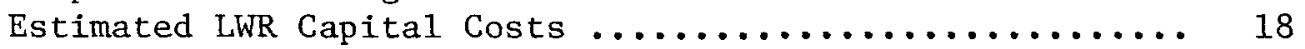

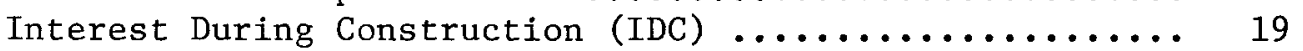

IV. LMFBR COST SCENARIOS AND COST RATIOS ............... 25

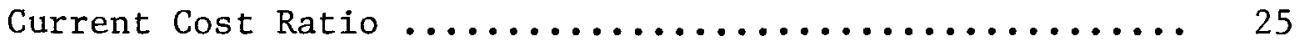

LMFBR Capital Cost Scenarios .................... 26

V. TIMING OF INTRODUCTION OF LMFBR $\ldots \ldots \ldots \ldots \ldots \ldots \ldots \ldots \ldots .36$

VI. EFFECT OF VARIATIONS IN ASSUMPTIONS .............. 37

LMFBR-LWR Cost Differences ....................... 37

Initial Capital Cost Ratios .................. 37

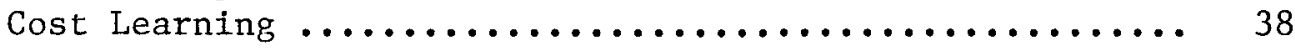

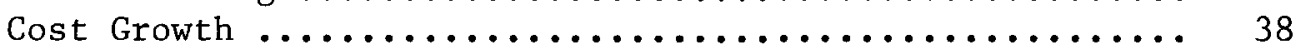

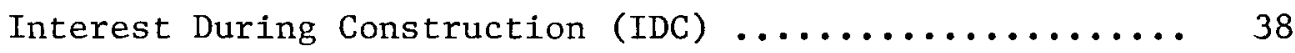

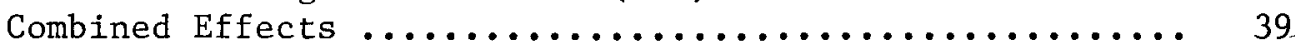

VII. A SIMPLIFIED METHOD FOR ESTIMATING COST RATIOS ......... 40

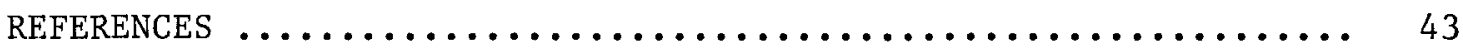

Appendix

A SUMMARY REVIEW OF LMFBR/LWR CAPITAL COSTS ............ 45 


\section{INTRODUCTION}

The economic benefit of fast breeder reactor power plants, now under development in a number of countries, is a major issue in international and domestic discussions of nuclear power and of nonproliferation policy. The liquid metal fast breeder reactor (LMFBR) is viewed as a possible successor to the current generation of thermal reactors, most of which are light water reactors (LWR). Whether and when fast breeder reactors, the LMFBR in particular, will replace LWRs will depend largely on the costs of generating electricity from each. The objective of this study is to estimate the relative capital costs of LWR and LMFBR power plants at years past the end of the century. These estimates can then be used as inputs for estimating the relative costs of electricity from LWRs and LMFBRs. *

Any capital cost estimate is usually accompanied by uncertainty, whether the subject of the estimate is a house, a ship, a factory, or

\footnotetext{
*A1though the cost of electricity from any nuclear plant is determined primarily by capital costs, it also depends on the capacity factor, the cost of fuel, and other operating expenses. The capacity factor (the amount of electricity that can actually be generated by a plant compared to the theoretical amount) was examined briefly in this study. Both LWR and LMFBR plants are designed according to "good engineering practice," but the designs carry with them no implicit guarantees on capacity factor. For the LWR, capacity factors appear to have varied considerably over time, but have been increasing in recent years. There appear to be differences that can be ascribed to the plant size, and perhaps to such variables as its age, type, and the operating utility. Since the observed differences are not now clearly understood, attempting to ascribe defensible differences between the capacity factors of future LWRs and LMFBRs was not possible without performing research that was beyond the scope of this study. We may speculate that the necessarily automated refueling sequence of the LMFBR, as compared with the more cumbersome head removal and manual refueling methods used in the current LWRs, could in principle give the LMFBR a somewhat greater capacity factor (unless the greater complexity were itself a cause of unreliability). In a similar speculative vein, the existence of additional heat transfer systems in the LMFBR, and their required maintenance, could potentially lower its capacity factor. The available data do not permit us to draw valid conclusions on relative capacity factors.
} 
a power plant. But the normal, or expected, uncertainty that accompanies capital cost estimates is compounded for nuclear power plants. Capital costs of LWR power plants have undergone dramatic increases during their 20-year history. The fact of the increases is unmistakable, but the causes are not completely understood. As a result, we are in a poor position to judge whether the costs will continue to rise as in the past, or even to guess whether the forces behind the historical cost increases will continue to exert pressure. There are substantial uncertainties in projecting future LWR plant costs.

For the liquid metal fast breeder reactor, we are in an even poorer position. No commercial LMFBR power plants have been built in the United States, and the experience of the rest of the world is limited and only available to us in generalities. To compare the costs of LWRs and LMFBRs, the nature of uncertainties in the deployment of LMFBRs must also be addressed.

We begin with an analysis of the capital cost estimates made in three LMFBR design studies carried out recently under Department of Energy/Electric Power Research Institute sponsorship. (1-3) The plants studied were all sodium-cooled loop systems, rated near 1000 MWe. The designs were based on current technology, conservatively chosen components (e.g., double-wall steam generator tubes), and conservative operating conditions. The studies included cost estimates, in current dollars, for a "fifth of kind" plant of the same basic design that might be built in later years.

In this report, these estimates are adjusted to a common basis and then are compared with a recent LWR capital cost estimate made by one of the companies that provided an LMFBR estimate. This comparison results in a cost ratio that varies from 1.25 to 1.50 , an of theard expected range. The questions which are then addressed are how these costs might change in the future as a result of cost learning effects, increased scope, " and variations of the date at which the LMFBR is introduced. To address these questions, two scenarios are used that

\footnotetext{
*Increased scope is often cited as the prime cause of cost increases experienced by LWRs.
} 
bracket a range of possible futures and result in different capital costs and capital cost ratios.

The two scenarios reflect a favorable environment for nuclear power (Scenario A), and an unfavorable environment (Scenario B). The capital cost estimates for the LWR in these scenarios stem in part from the results of a statistical study of past LWR capital costs. (4)

Reference 4 gives a regression equation describing the large LWR capital cost increases in recent years. A scenario might have been adopted that assumed these past increases would continue unabated in the future. Such a scenario was deemed implausible, however, because a linear extrapolation of the past data was judged to be an incorrect projection of the future that would quickly lead to such high costs that the plants would not be economically viable, and would not be built in reality.

Both Scenarios A and B assume a major departure from past trends in LWR capital costs. Scenario A assumes a vigorous nuclear enterprise, with about 400 LWR plants coming into operation between 1990 and 2010 . Scenario B assumes a much smaller addition of LWR capacity, about 100 plants in the same period. In Scenario A, LWR plant cost increases end in the near future, around 1980, and decrease thereafter. In Scenario $B$, LWR costs rise to a higher level and then remain constant beyond about 1990 .

For the LMFBR, Scenario A assumes that the regulatory climate and public attitudes toward the system have stabilized during the demonstration plant period preceding commercial plant deployment. Capital costs for the LMFBR are essentially determined by technological characteristics of the system, and decrease modestly as deployment continues after initial introduction in the early 2000s. The LMFBR/LWR cost ratio approaches the asymptote of about 1.2, which is inherently due to technical differences between the two systems. Since both LWR costs and the LMFBR/LWR cost ratio are low in this scenario, it represents a favorable cost picture for the LMFBR.

In Scenario B, it is assumed that the LMFBR encounters an initial period of increasing regulatory requirements and public scrutiny ana1ogous to that which the LWR experienced. The costs of plants beyond 
the initial commercial LMFBRs rise until these issues become resolved, then slowly stabilize and turn down. This scenario, then, represents an unfavorable cost picture for the LMFBR, with both high LWR costs and a high LMFBR/LWR ratio.

Neither scenario is necessarily extreme. Technical advances can be conjectured for Scenario A, while unforeseen safety, safeguard, and institutional requirements might arise in Scenario $B$, to further lower or raise LMFBR capital costs. However, it appears internally contradictory to go much beyond Scenario B, since the likelihood of any LMFBR plants being built if such conditions prevailed appears remote.

The events that affect LMFBR costs are taken as analogies to the events that affected LWR costs. Not explicitly included in either scenario is the effect of any government involvement in LMFBR commercial deployment, which might result in unique internal project forces that could affect cost significantly. 
II. CAPITAL COSTS FOR LMFBR POWER PLANTS

A number of capital cost estimates have been made for liquid metal fast breeder reactor plants by companies in the nuclear hardware business. This section discusses estimates provided to Rand by three companies: Atomics International (AI), General Electric (GE), and Westinghouse. As received by Rand, the three estimates were made on differing bases. Plant size was similar but not identical, estimates were made in different year dollars, and some cost categories that should have been identically treated were not. In addition, the three estimates reflected three different plant designs. Although each estimate was made according to Federal Power Commission (FPC)* categories, there is sufficient latitude in the categories that consistent use of them was not assured, despite the fact that each of the estimates was carefully made on a very detailed level. One purpose of this section is to document the steps that were taken to put the estimates on a comparable basis. Comparable basis was defined as:

- No cost categories are omitted

- Estimates are based on a "fifth of kind" LMFBR

o Costs are expressed in 1978 dollars per kWe

- Interest during construction and other cost categories unrelated to the specific design of the plant are treated similarly.

Once this was done, any remaining differences would be due to differences in design or in estimating techniques.

An independent analysis of the three LMFBR cost estimates was carried out by Southern Science Applications, Inc. (SSAI) of Dunedin, Florida, under a subcontract to Rand. Their task was to identify any omissions or other anomalies in the estimates, and to focus particularly on differences between the LMFBR and a typical LWR. Their study

\footnotetext{
Now the Federal Energy Regulatory Commission (FERC).
} 
resulted in another set of adjusted LMFBR costs that will be presented in Sec. III, along with the Rand estimates.

The SSAI report is included as the appendix. It restructured the original estimates to conform with the CONCEPT code of accounts.

\section{ESTIMATES FROM THE REACTOR MANUFACTURERS}

The estimates are presented as provided to Rand. A11 of the data are not given, because sometimes voluminous details were provided to illustrate the care that was exercised in making the estimates. Selected tables reflect the data obtained in the form that they were given to Rand, and those who provided them should recognize them without difficulty.

\section{Atomics International--Burns and Roe}

This estimate, shown in Table 1, was made for a 1000 MWe LMFBR and was presented in 1977 dollars.

Table 1

AI ESTIMATE

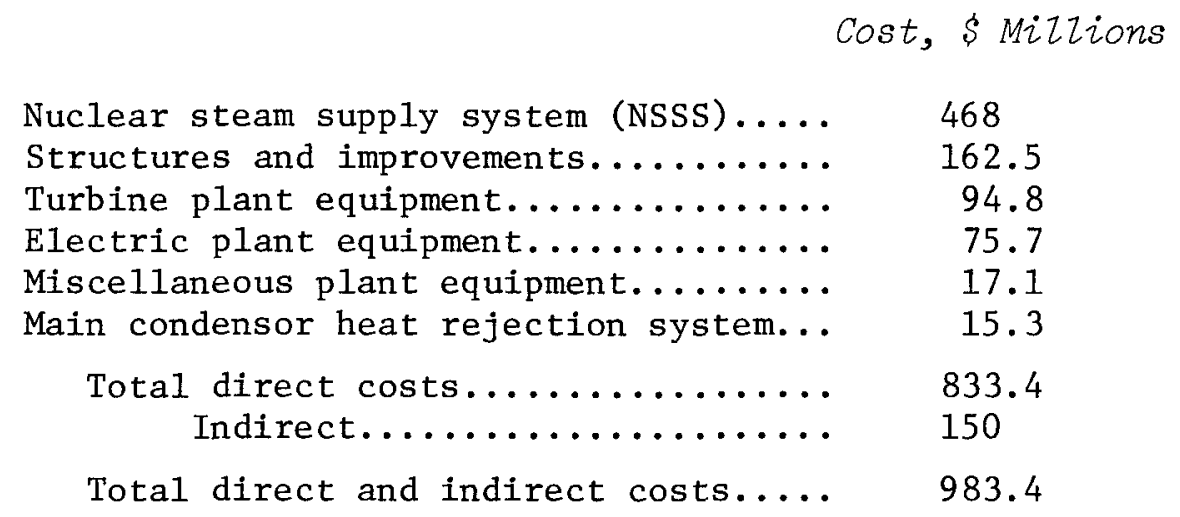

It was noted in this estimate that no provision had been made for land purchase, and that a specific entry for contingencies had not been included. The estimate also did not include interest during construction. Inquiries about these items resulted in AI's assurance that the contingencies expected had been built in to the individual estimates. Thus the $\$ 468$ million that was estimated for the nuclear steam supply 
system included contingencies to cover uncertainties. Land costs will be added later.

\section{General Electric--Bechtel}

The GE estimate initially provided was for a 900 MWe plant and was in 1977 dollars. Interest during construction was included by using 8 percent for $31 / 2$ years, which implies a construction time of 7 years, and was calculated as noncompounding interest, i.e., 28 percent of the direct and indirect costs was estimated to be interest. The estimate is shown in Table 2 .

Table 2

GE ESTIMATE

Cost, \$Mizzions

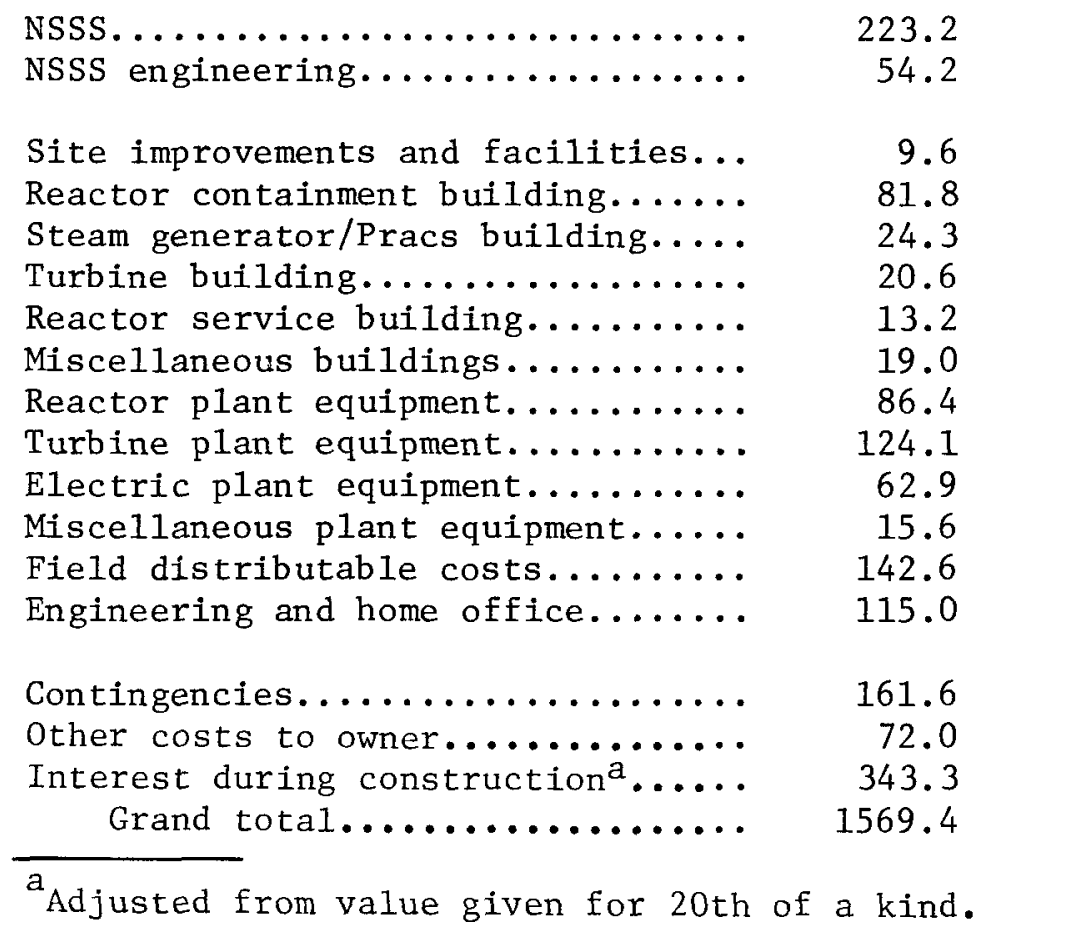

Westinghouse--Stone and Webster

Westinghouse provided an estimate for a 1000 MWe plant in 1978 dollars, which, like the AI estimate and the revised GE estimate, was for 
a "fifth of kind" plant. Initially this estimate had no specific contingency costs, and after discussion with Westinghouse it was determined that, like AI, much of the estimated contingency for uncertainty had been included in the individual line items. This had not been done on the balance of plant items, however, and at their suggestion the estimate was modified to include 5 to 10 percent of the balance of plant as a specific contingency. This entry is shown below as though it had been included in the original data.

Interest during construction was estimated at a 9 percent rate, compounded for a period varying from about $41 / 2$ to $51 / 2$ years to produce the range shown. The estimate appears in Table 3.

Table 3

WESTINGHOUSE ESTIMATE

Cost, \$ Mizzions

\begin{tabular}{|c|c|}
\hline NSSS. & $475-600$ \\
\hline Turbine generator system........ & $83-105$ \\
\hline Buildings and structures......... & $102-164$ \\
\hline Electrical plant............. & 54 \\
\hline 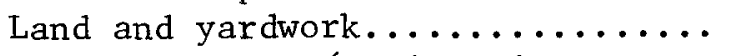 & 10 \\
\hline $\begin{array}{l}\text { Indirect costs (engineering } \\
\text { services, site construction, }\end{array}$ & \\
\hline owner, and other costs)....... & $120-160$ \\
\hline Contingency................ & $19-49$ \\
\hline Interest during construction ${ }^{\mathrm{a}} . .$. & $430-610$ \\
\hline Total plant............... & $1293-1752$ \\
\hline
\end{tabular}

\section{ADJUSTMENTS TO ESTIMATES}

Initially it had been hoped that the various estimates could be compared on a disaggregated basis, but it soon became apparent that this would be unwise and produce misleading impressions. The reasons involve the flexibility of the FPC cost format and variations in the way in which each contractor made his estimate. For example, uncertainty is frequently included as a contingency, and is carried in the 
estimate as a separate line item. But sometimes it makes more sense to account for this uncertainty at a much more detailed leve1, and some estimators did that. As a result, costs for any single line item may appear to be widely different from one estimate to another, whereas in reality the differences may only be due to differing definitions and treatment of uncertainty. Consequently, no comparisons should be attempted at a disaggregate level, and no implications should be drawn from the relative cost of any specific line item. For example, if the NSSS cost in one estimate appears as a different fraction of the total costs than in another estimate, no conclusions should be drawn.

Specific adjustments to the estimates were made as follows:

- Land costs, added to the AI estimate, were equalized among the estimates at $\$ 10$ million.

- Changes were made to the GE estimate so that it represented a "fifth of kind" plant.

- The GE and AI estimates were adjusted from 1977 dollars to $1 / 1 / 78$ dollars by the ratio of the Handy-Whitman index values for those two years. This raised the 1977 dollar estimate by 5 percent.*

- The GE costs were adjusted to costs per kWe by dividing the estimated costs by 0.9 . It could be argued that a further adjustment should have been made in this process because the GE design was for a 900 MWe plant compared with 1000 MWe plants designed by $A I$ and Westinghouse. Had GE designed a 1000 MWe plant, there may have been economies of scale that would have reduced the costs per $\mathrm{kWe}$. The subject is not analyzed here. If economies of scale were applicable in this case, unit costs would be reduced about 3 percent.

*This adjustment is from average 1977 dollars to $1 / 1 / 78$ dollars, or about a 6-month change. 
- Interest during construction was removed from both the GE and Westinghouse estimates to put all three estimates of the direct plus indirect costs on a comparable basis. Interest during construction can be added later as required for analysis.

The results of these adjustments are shown in Table 4, together with SSAI's estimates.

Table 4

LMFBR DIRECT PLUS INDIRECT CAPITAL COST ESTIMATES

(Excluding IDC, 1978 dollars per kWe)

\begin{tabular}{c|c|c}
\hline Estimator & Rand & SSAI \\
\hline AI & 1043 & 1105 \\
GE & 1495 & 1326 \\
Westinghouse & $863-1142$ & $969-1248$ \\
\hline
\end{tabular}




\section{ESTIMATES OF LWR COSTS}

LWR costs need to be estimated for two purposes. The first is for comparison with the LMFBR cost estimates, so that an initial capital cost ratio can be estimated. For this purpose, the LWR cost must be one that is contemporary with the LMFBR, and specifically for an LWR that begins construction in 1977, which is the design basis for the LMFBR. This was anticipated by GE, who provided an LWR cost estimate that was designed to be used with their LMFBR cost estimate on a comparative basis. A cost ratio could then be derived that would be valid at the time that the fifth LMFBR reached commercial operation. LWR cost estimates were also suggested by $\mathrm{AI}$ and Westinghouse, but they were taken from the literature and were judged not to be consistent with their LMFBR estimates. Consequently they were not used in this analysis.

The GE LWR estimate was $\$ 770$ million in 1977 dollars for a 900 MWe plant, not including interest during construction. This figure can be adjusted to $1 / 1 / 78$ dollars per $k W e$ in the same way that the LMFBR costs were, by dividing by 0.9 and multiplying by 1.05 , which is the HandyWhitman construction cost index ratio. The result is $\$ 900$ per $\mathrm{kWe}$, not including interest during construction, and this value was intended by GE to be compared with their LMFBR estimate.

The second purpose of estimating LWR costs is to project them, so that LMFBR/LWR cost ratios may be estimated at various dates in the future. For this purpose, we presume that the rapid LWR capital cost increases experienced in the past will be modified in the future, and have based the projected costs on this assumption combined with the statistical findings of Ref. 4. The initial LMFBR/LWR cost ratios are obtained by using the $\$ 900$ per kWe LWR estimated by GE, which is consistent with the assumptions made for the LWR projected costs.

We next develop LWR cost estimates based on this general premise, but in two different scenarios. In Scenario A, low LWR costs are realized, and in Scenario B, less optimistic, LWR costs are high. These scenarios will be paired later with similar scenarios for the LMFBR. 


\section{LWR DEPLOYMENT SCHEDULES}

We begin by using the Department of Energy LWR schedule ${ }^{(5)}$ reproduced in Table 5. This schedule shows that 194 power plants are expected to be in commercial operation in 1989, and that a total of 216 plants are expected after 1989. Using the 194 power plants in 1989 as a point of departure, we postulate a healthy industry that would be consistent with a low-cost LWR. ${ }^{*}$ Power plants are built at a steady rate, with 400 of them being in commercial operation in 2000 . At a nominal size of 1000 MWe, this is equivalent to a generating capacity of 400 GWe in year 2000. The projected rate of construction continues, and about 960 plants are in commercial operation in 2026. For the purpose of estimating capital costs, the exact number of plants projected at periods beyond 2000 is not too important. The main point is that the industry is a healthy one in this scenario, which we designate Scenario $\mathrm{A}$.

For Scenario B, we hypothesize a much lower construction schedule, with capital costs that continue to rise. Again using 194 plants in 1989 as a departure point, we estimate that 250 plants are in commercial operation in 2000.

Both deployment schedules are illustrated in Fig. 1.

$\underline{\text { LWR CONSTRUCTION TIME }}^{\dagger}$

Construction time is important to the LWR analysis for two reasons. The first is that schedules of power plants, such as those listed in Table 5, are usually given in terms of their date of commercial operation. As will become apparent later, this schedule needs to be translated into one that refers to the date on which construction of the plants starts. The construction time is the key to this translation. The second reason construction time is important is that the cost of interest during construction (IDC) is a function of construction time, which must be known.

\footnotetext{
*And, as we will later see, with the deployment of LMFBRs.

†Construction time is defined as the period from the date the construction permit was issued (CPIS) to the date the operating license was issued (OLIS).
} 
Table 5

NUMBER OF LIGHT WATER REACTORS IN COMMERCIAL OPERATION VERSUS TIME

\begin{tabular}{c|r|c|c|c}
\hline \multirow{2}{*}{ Year } & \multicolumn{2}{|c|}{ MWe Net } & \multicolumn{2}{c}{ No. of Units } \\
\cline { 2 - 5 } & Annual & Cumulative & Annual & Cumulative \\
\hline Through 1975 & & 37,341 & & 55 \\
1976 & 3,749 & 41,090 & 4 & 59 \\
1977 & 6,381 & 47,471 & 7 & 66 \\
1978 & 6,034 & 53,505 & 7 & 73 \\
1979 & 7,711 & 61,216 & 7 & 80 \\
1980 & 11,417 & 72,633 & 11 & 91 \\
1981 & 13,418 & 86,051 & 12 & 103 \\
1982 & 12,704 & 98,755 & 12 & 115 \\
1983 & 14,062 & 112,818 & 13 & 128 \\
1984 & 19,260 & 132,079 & 18 & 146 \\
1985 & 13,732 & 145,811 & 12 & 158 \\
1986 & 12,684 & 158,495 & 11 & 169 \\
1987 & 8,953 & 167,448 & 8 & 177 \\
1988 & 11,363 & 178,811 & 10 & 187 \\
1989 & 7,878 & 186,689 & 7 & 194 \\
1990 on & 17,798 & 204,487 & 15 & 209 \\
Indefinite & 7,723 & 212,210 & 7 & 216 \\
\hline
\end{tabular}

SOURCE: Ref. 5 .

Reference 4, which specifically addresses construction time, found that for construction permits issued between 1967 and 1972 there was a linear increase in average construction time of about 4.5 months per year, when the effects of other variables were accounted for. ${ }^{*}$ Taken at face value, a projection of construction times using this analysis would imply unreasonable values towards the end of the century. Instead, it is assumed that the observed linear increase will not continue indefinitely, but will bend and cease to increase further at some point. Solving the regression equation ${ }^{\dagger}$ developed in the statistical

\footnotetext{
* Increased construction time is thought to be at least partially due to increased scope, which results from greater regulation to assume safety and environmental protection.

${ }^{\dagger}$ Construction time in months $=4.5 \mathrm{CPIS}+0.04 \mathrm{SIZE}-8 \mathrm{LN}-270$, where CPIS $=$ date construction period issued $(1972=72)$; SIZE = plant size, MWe; and $\mathrm{LN}=$ natural logarithm of cumulative number of plants built by an architect engineer.
} 


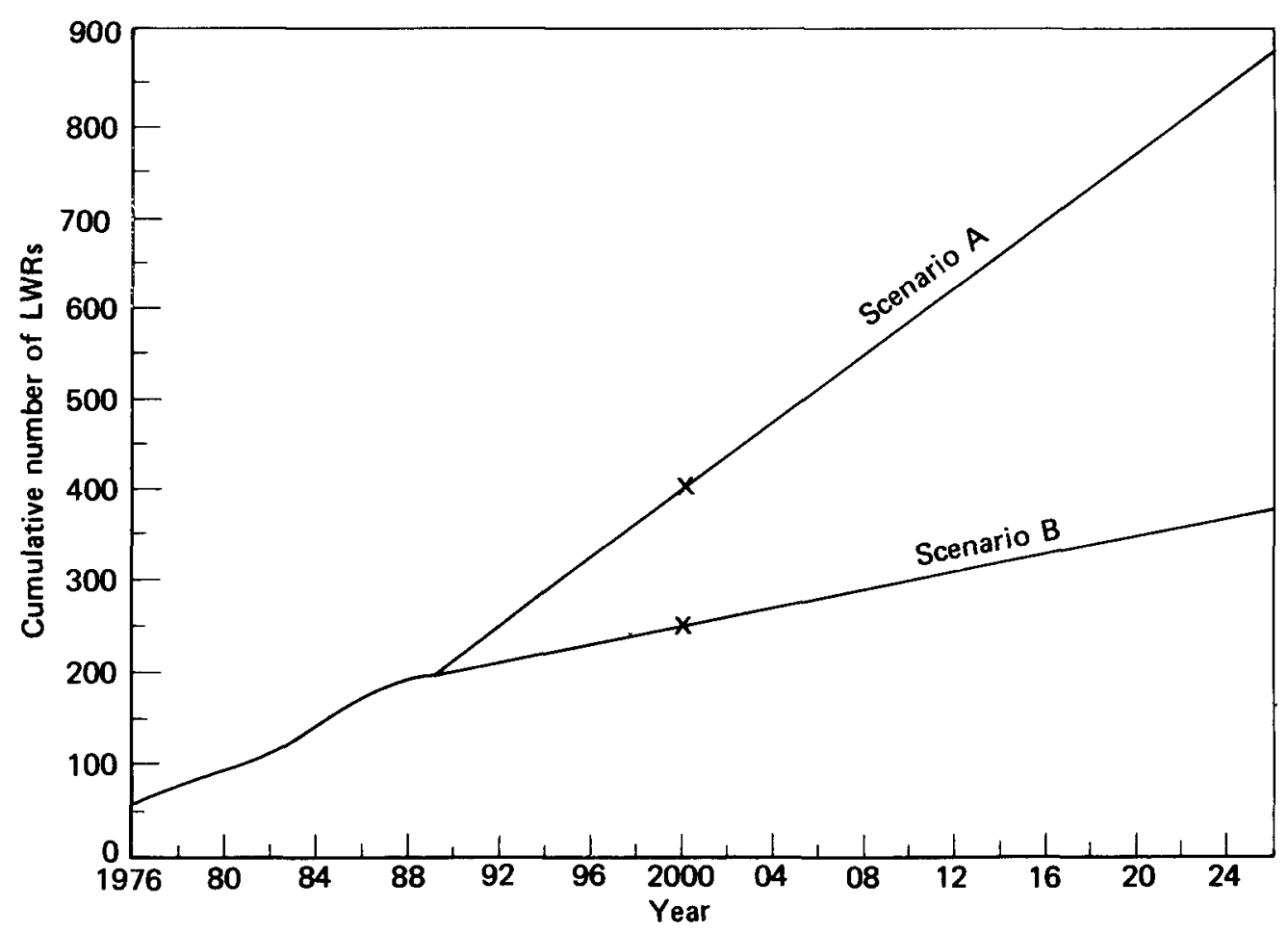

Fig. 1 - Number of LWR $s$ in commercial operation

analysis for construction permits issued in mid-1972, the last point in the regression data base, and setting the other equation variables at reasonable (and fixed) values, yields an estimate of 70 months for the construction of a 1000 MWe plant. We assume that this is the last point on the linear curve, which begins to bend over thereafter.

For Scenario A, we project a fairly rapid bending of the curve, reaching a maximum of about 74 months in 1976 through 1979, and then a gradual diminishing of time thereafter, eventually stabilizing at about 69 months in the ear1y 1990s.

For Scenario $B$, we project that construction times reach a maximum of 80 months for construction permits issued in 1979, and that this time remains constant thereafter. The regression equation actually shows that there is a reduction in construction time through learning, as more plants are built. But in Scenario $B$, very few plants are built, which minimizes the learning effect. 
Curves for Scenarios $A$ and $B$ are shown in Fig. 2, together with a curve that represents merely a straight linear extrapolation of past trends for comparison.

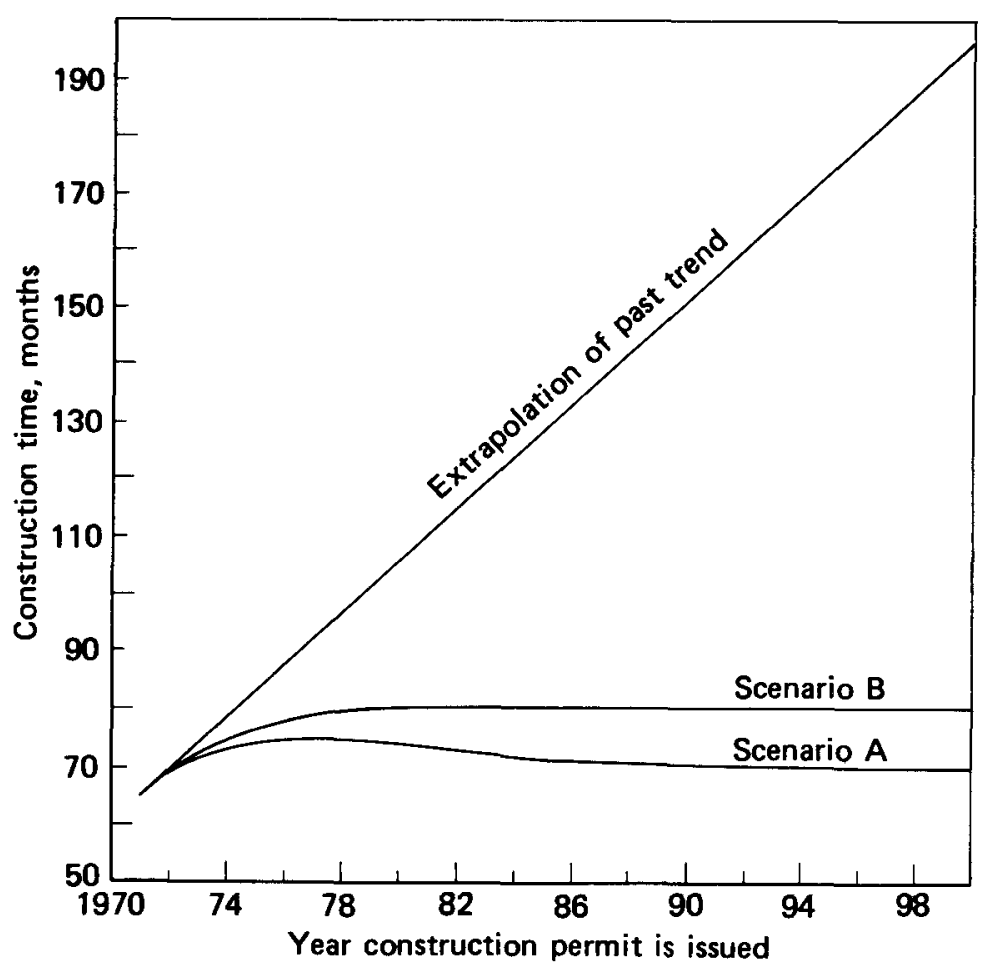

Fig. 2-Construction time as a function of year of construction permit

\section{CONSTRUCTION START DATES (CPIS)}

With the construction time information for both scenarios, the relation of the date of commercial operation to CPIS can be established. CPIS is simply the date of commercial operation minus the construction time and minus an additional six months that represents the period from the completion of construction until the plant reaches commercial operation. The curves expressing the relationship are shown in Fig. 3, again with the regression analysis curve for comparison. 


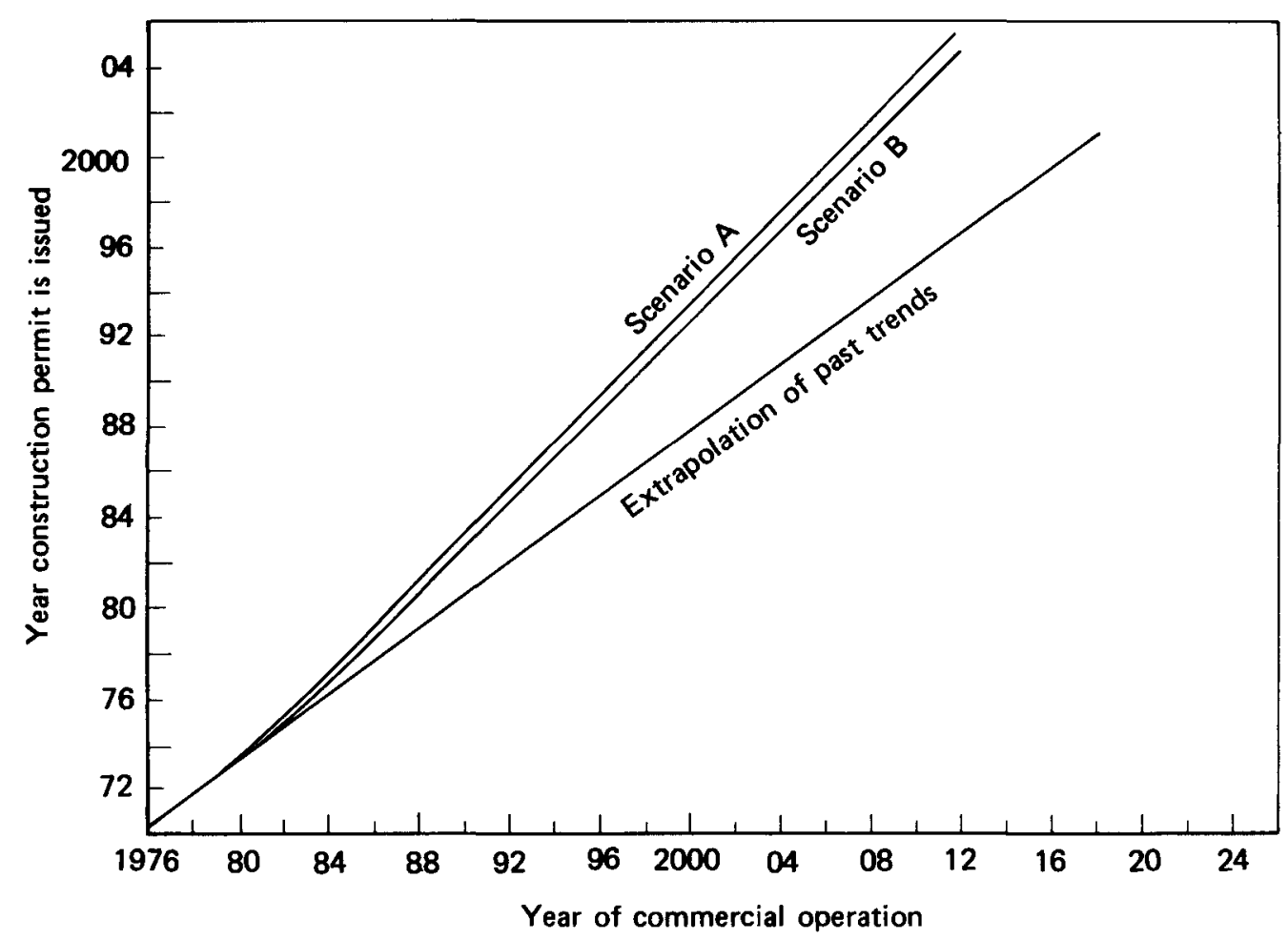

Fig. 3-Date of commercial operation as a function of date of construction permit (see Fig. 2)

\section{TEMPORAL COST CHANGES}

Power plant capital costs have increased rapidly in the past, and the statistical results of Ref. 4 indicate that the rate of increase was about $\$ 141$ per year for the period CPIS $=1967$ to mid-1972, when corrected for the effect of other variables. Again, taken at face value, this projects unlikely costs towards the end of the century. As with construction time, the assumption is made again that the observed linear increase will taper off. We assume that the cumulative temporal cost increases will be simply in direct proportion to the changes in the construction times shown in Fig. 2. This assumption is plausible, in that it can be argued that a stabilization of the plant scope would result in a stabilization of both plant construction time and plant cost. Using this assumption, the cumulative temporal cost increases beyond 1971 are estimated as though they were proportional to the construction time changes. 
The curves shown in Fig. 4 are the results for the two scenarios. The constant of proportionality is the $\$ 141$ per year that was obtained in the regression analysis. For example, between 1971 and 1981 the regression analysis shows a schedule increase of 45 months, whereas Scenarios $A$ and $B$ show increases of 8 and 15 months, respectively. Instead of the $\$ 1410$ increase during that 10 year period predicted by the linear regression, Scenario $A$ has an increase of $(8 / 45) \times \$ 1410=\$ 250$, and Scenario $B$ has an increase of $(15 / 45) \times \$ 1410=\$ 470$.

For Scenario B, no further construction time or temporal cost increases are projected past CPIS $=1979$. Since 1979 is here, the scenario implies that all increases in construction costs that are due, for example, to increased plant scope and regulatory changes are virtually over. This implication may be startling to an industry that has

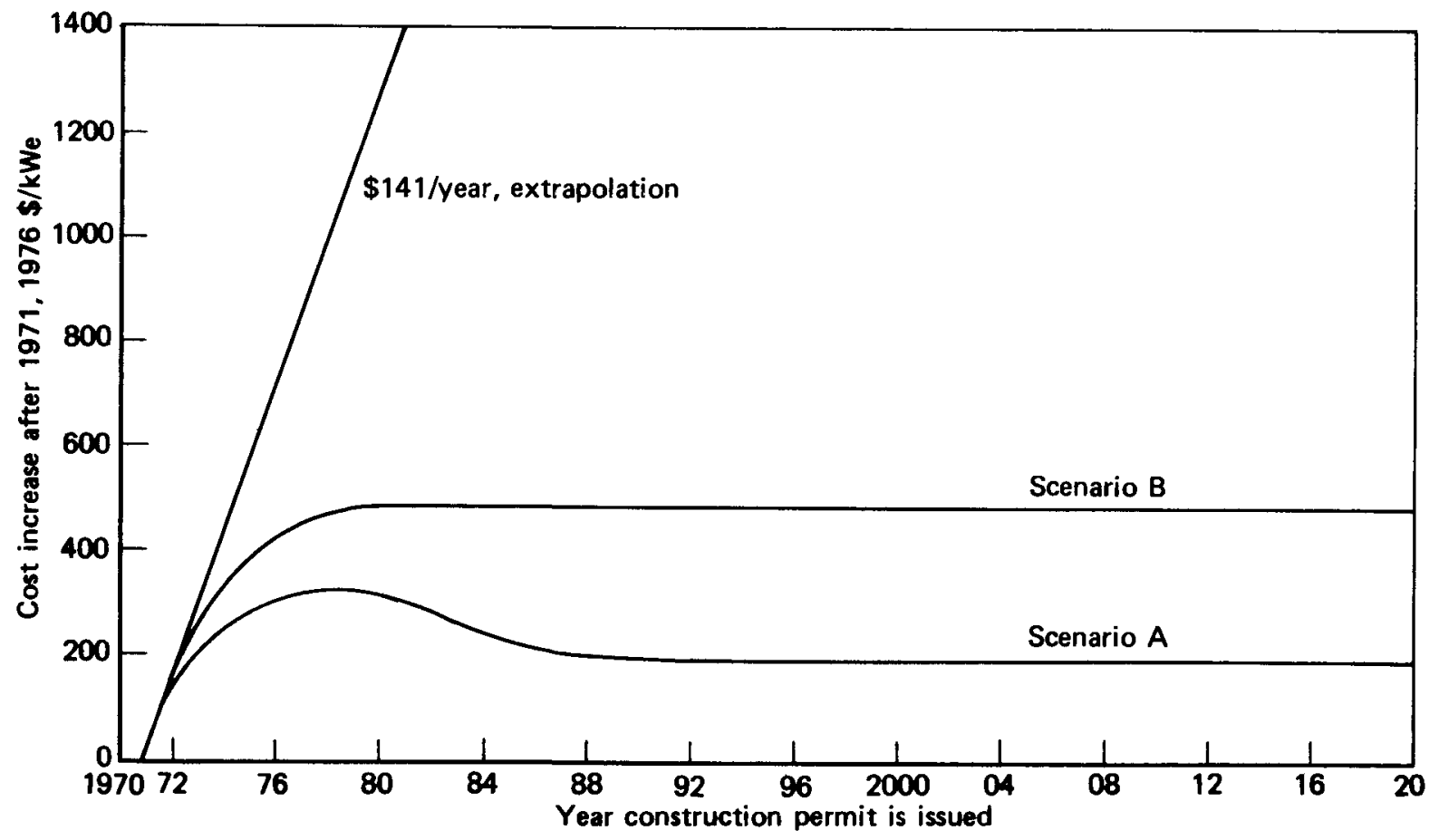

Fig. 4-Cumulative temporal LWR cost increases 
been besieged by temporal cost increases, and it may be even more startling that it is associated with the scenario having the higher costs.

For Scenario A, the implications are even more dramatic. Here we suggest that temporal cost changes peak at CPIS $=1976$ to 1979 , and then drop, stabilizing at about 1990. This implies that LWR plants that began construction between 1976 and 1979 will experience no further temporal cost increases, and that plants that begin construction subsequent to 1979 will actually experience diminished scope and regulation, resulting in negative temporal cost changes. We speculate that there now is sufficient experience with LWRs that certain conservative regulations might be relaxed to conform with experience. These relaxations can result in decreases in plant costs, i.e., negative temporal cost changes.

\section{ESTIMATED LWR CAPITAL COSTS}

We now have all of the elements required to project capital costs beyond the range of data used in the regression analysis. These elements are the costs resulting from the use of the equation in 1971 , the assumed temporal cost changes beyond 1971, and the schedule of plants to be built, which allows the cost learning effect to be taken into account. An assumption needs to be made about the learning effect, which is principally attributed to the architect engineer and not to the industry as a whole. For this study, it has been assumed that one architect engineer builds half of the plants. Therefore the learning effect is estimated by using half of the total number of plants as the equation input. This probably overstates the average learning effect, ${ }^{*}$ but not so as to distort the analysis. The regression equation is

$$
\begin{gathered}
\text { Capital cost }(\$ 1976)=141 \text { CPIS }-8885-0.2 \text { SIZE } \\
+92 \text { TOWER }+128 \text { LOC1 }-72 \mathrm{LN},
\end{gathered}
$$

\footnotetext{
* Since the average architect engineer will not have constructed this many plants, this assumption maximizes the learning effect for both LWR scenarios. Similar treatment will be used in the LMFBR scenarios. The result is that the estimates are those of plants that enjoy the maximum benefits of learning.
} 
where CPIS = construction permit issuance date

SIZE = plant size, MWe

TOWER $=1$ if there is a cooling tower

LOC1 $=1$ if the plant is located in FPC Region I

$\mathrm{LN}=$ natural logarithm of $\mathrm{N}$, the cumulative number of plants built by an architect engineer.

Setting size $=1000$ MWe, TOWER and LOC1 at the sample means, ${ }^{*}$

$\mathrm{N}=21$, and CPIS $=71$, we determine that the estimated capital cost

for a plant on which construction begins in 1971 is $\$ 780$ per $\mathrm{kWe}$ ( $\$$

1976), or 997 - 72 LN. The costs for plants built subsequent to

CPIS $=71$ will be

$$
\$ 997 \text { - } 72 \mathrm{LN}+\text { temporal cost change, }
$$

again in 1976 dollars. Using this equation, the convention that half of the plants built subsequent to 1971 are built by the same architect engineer, and the temporal cost changes shown in Fig. 4, we solve for capital costs from CPIS $=1972$ onward. These are listed in Table 6 and illustrated in Fig. 5, where they are plotted against CPIS.

Two further steps are required. The capital costs have been estimated in 1976 dollars, since the regression equation was derived in that form. We first convert the costs so obtained to $1 / 1 / 78$ dollars by multiplying the 1976 dollar costs by the ratio of the 1/1/78 HandyWhitman power plant construction cost index to the same index for 1976. This ratio is 1.10 . The second step is to translate CPIS to the date of commercial operation; Fig. 3 is used for this purpose. The results are listed in Table 7 and illustrated in Fig. 6.

INTEREST DURING CONSTRUCTION (IDC)

The costs estimated above represent total capital costs to a utility, and thus include interest during construction. To use the costs estimated in this study in an analysis in which interest costs

\footnotetext{
* The average values in the data base from which the regression equation was developed.
} 
Table 6

CAPITAL COSTS BEYOND 1972

(\$ 1976)

\begin{tabular}{|c|c|c|c|c|c|c|c|}
\hline \multicolumn{4}{|c|}{ Scenario A } & \multicolumn{4}{|c|}{ Scenario B } \\
\hline CPIS & $\mathrm{N}^{\mathrm{a}}$ & $\begin{array}{l}\text { Cumulative } \\
\text { Temporal } \\
\text { Costs } \\
\text { (Fig. 4) }\end{array}$ & Cost & CPIS & $\mathrm{N}^{\mathrm{a}}$ & $\begin{array}{c}\text { Cumulative } \\
\text { Temporal } \\
\text { Costs } \\
\text { (Fig. 4) }\end{array}$ & Cost \\
\hline 1972 & 32 & 100 & 850 & 1972 & 32 & 125 & 870 \\
\hline 1973 & 37 & 180 & & 1973 & 37 & 235 & \\
\hline 1974 & 43 & 240 & 970 & 1974 & 43 & 320 & 1050 \\
\hline 1975 & 49 & 300 & & 1975 & 49 & 380 & \\
\hline 1976 & 56 & 310 & 1020 & 1976 & 56 & 420 & 1130 \\
\hline 1977 & 65 & 315 & 1010 & 1977 & 65 & 450 & \\
\hline 1978 & 71 & 315 & & 1978 & 71 & 470 & 1160 \\
\hline 1979 & 76 & 310 & 990 & 1979 & 76 & 480 & \\
\hline 1980 & 80 & 295 & 980 & 1980 & 80 & 480 & 1160 \\
\hline 1981 & 85 & 275 & & 1981 & 85 & 480 & \\
\hline 1982 & 89 & 255 & & 1982 & 89 & 480 & \\
\hline 1983 & 98 & 240 & & 1983 & 91 & 480 & \\
\hline 1984 & 107 & 225 & & 1984 & 94 & 480 & \\
\hline 1985 & 117 & 215 & 870 & 1985 & 99 & 480 & 1150 \\
\hline 1986 & 126 & 205 & & 1986 & 102 & 480 & \\
\hline 1987 & 136 & 200 & & 1987 & 104 & 480 & \\
\hline 1988 & 145 & 190 & & 1988 & 107 & 480 & \\
\hline 1989 & 154 & 190 & & 1989 & 109 & 480 & \\
\hline 1990 & 164 & 190 & 820 & 1990 & 112 & 480 & 1140 \\
\hline 1992 & 182 & 190 & & 1992 & 114 & 480 & \\
\hline 1994 & 201 & 190 & & 1994 & 119 & 480 & \\
\hline 1996 & 220 & 190 & & 1996 & 124 & 480 & \\
\hline 1998 & 238 & 190 & & 1998 & 192 & 480 & \\
\hline 2000 & 257 & 190 & 790 & 2000 & 134 & 480 & 1120 \\
\hline 2026 & 476 & 190 & 740 & 2026 & 182 & 480 & 1100 \\
\hline
\end{tabular}

${ }^{\mathrm{a}}$ See text for definition.

are varied parametrically, it is necessary to identify and separate the IDC from the total costs. The fraction of total plant capital costs that is IDC is represented by the expression

$$
1-\frac{1}{1+(\text { interest rate } \times \text { interest period })} \text {. }
$$




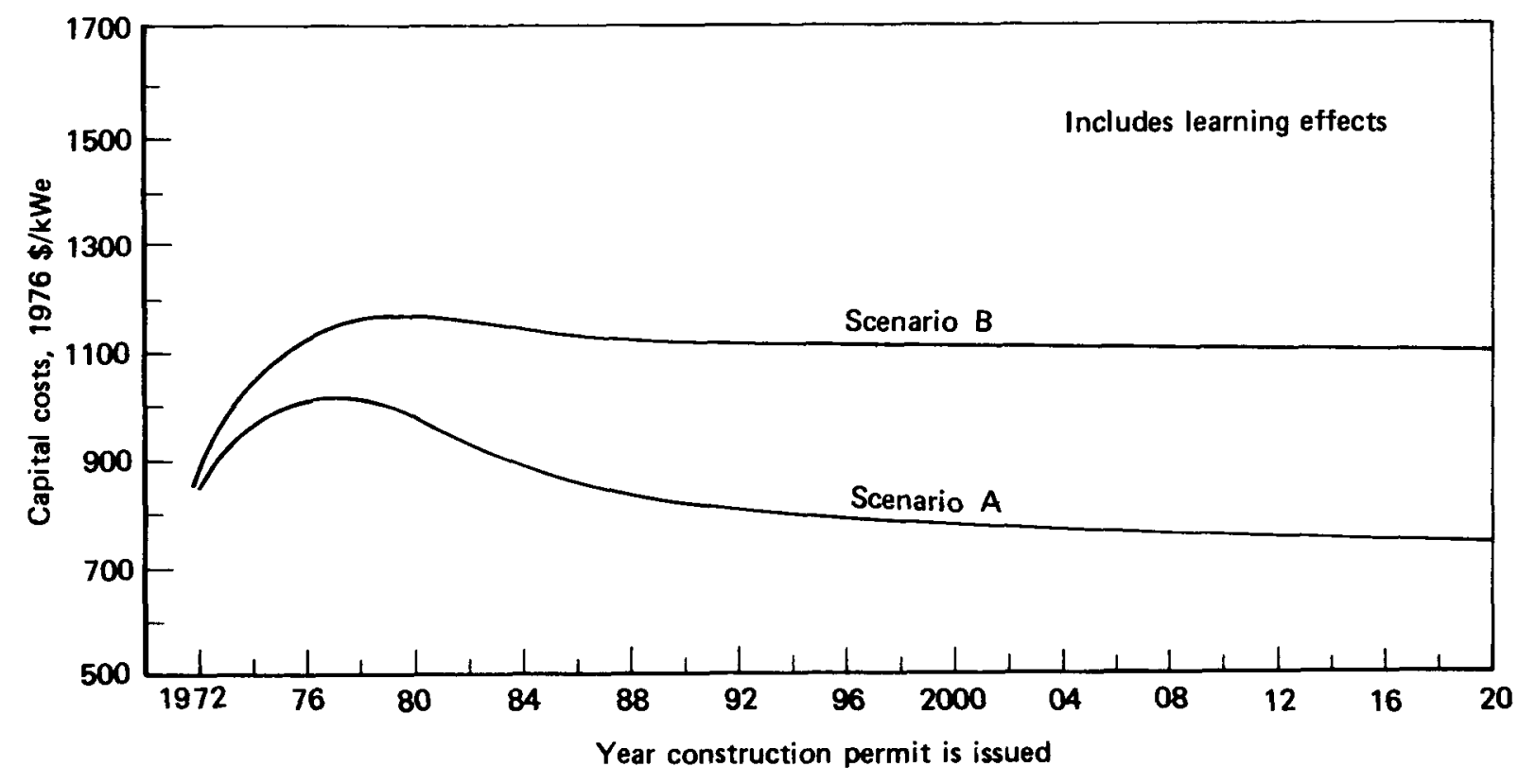

Fig. 5-Estimated total capital costs (from Table 6)

During the time covered by the regression analysis of LWR power plants, it is understood that the effective interest rate to utilities probably averaged 8 percent and did not vary a great deal. ${ }^{*}$ The interest period has been variously identified as one-third of the total project time ${ }^{\dagger}$ or one-half of the construction time, which are about equivalent. For this study, we will use one-half of the construction time. In the discussion above, it was shown that the average construction time lengthened steadily from CPIS $=67$ to CPIS $=72$, and thus it would be expected that the IDC component would become larger and swell the total costs. The

\footnotetext{
*Harvey Wycoff, Commonwealth Edison Co., private communication.

Total project time includes the time required to obtain a construction permit, the construction time, and about six months between the end of construction and the time the plant is declared to be in commercial operation.
} 
Table 7

CONVERSION OF COSTS TO 1978 DOLLARS AND CONVERSION OF CPIS TO YEAR OF COMMERCIAL OPERATION

\begin{tabular}{|c|c|c|c|c|c|c|c|}
\hline \multicolumn{4}{|c|}{ Scenario A } & \multicolumn{4}{|c|}{ Scenario B } \\
\hline $\begin{array}{l}\text { Year of } \\
\text { Commercial } \\
\text { Operation }\end{array}$ & $\begin{array}{c}\text { CPIS } \\
(\text { Fig. 3) }\end{array}$ & $\begin{array}{l}\text { Cost, } \\
1976 \\
\text { Dollars } \\
\text { (Fig. 5) }\end{array}$ & $\begin{array}{c}\text { Cost, } \\
1978 \\
\text { Dollars }\end{array}$ & $\begin{array}{l}\text { Year of } \\
\text { Commercial } \\
\text { Operation }\end{array}$ & $\begin{array}{c}\text { CPIS } \\
(\text { Fig. } 3)\end{array}$ & $\begin{array}{l}\text { Cost, } \\
1976 \\
\text { Dollars } \\
\text { (Fig. 5) }\end{array}$ & $\begin{array}{l}\text { Cost, } \\
1978 \\
\text { Dollars }\end{array}$ \\
\hline 1979 & 1973 & 900 & 990 & 1979 & 1973 & 940 & 1030 \\
\hline 1980 & 1974 & 950 & 1050 & 1980 & 1974 & 1000 & 1100 \\
\hline 1981 & 1974 & 980 & 1080 & 1981 & 1974 & 1060 & 1170 \\
\hline 1982 & 1975 & 1000 & 1100 & 1982 & 1975 & 1100 & 1200 \\
\hline 1983 & 1976 & 1010 & 1110 & 1983 & 1976 & 1130 & 1240 \\
\hline 1984 & 1977 & 1020 & 1120 & 1984 & 1977 & 1150 & 1270 \\
\hline 1985 & 1978 & 1010 & 1110 & 1985 & 1978 & 1160 & 1280 \\
\hline 1986 & 1979 & 990 & 1090 & 1986 & 1979 & 1160 & 1280 \\
\hline 1987 & 1980 & 980 & 1070 & 1987 & 1980 & 1160 & 1280 \\
\hline 1988 & 1981 & 960 & 1060 & 1988 & 1981 & 1160 & 1280 \\
\hline 1989 & 1983 & 930 & 1020 & 1989 & 1982 & 1160 & 1280 \\
\hline 1990 & 1084 & 920 & 1000 & 1993 & 1985 & 1150 & 1260 \\
\hline 1992 & 1986 & 870 & 960 & 2000 & 1993 & 1130 & 1240 \\
\hline 1998 & 1992 & 820 & 900 & 2005 & 1998 & 1120 & 1240 \\
\hline 2000 & 1994 & 820 & 900 & 2010 & 2003 & 1120 & 1240 \\
\hline 2005 & 1999 & 790 & 860 & & & & \\
\hline 2010 & 2004 & 790 & 860 & & & & \\
\hline
\end{tabular}

cost regression reflects this situation implicitly as a part of the temporal cost coefficient. However, since we assume that the effective interest rate during the period covered by the statistical analysis was constant, we can isolate the implicit IDC from the above cost projections by using this constant interest rate and the construction times that have been assumed for the two cost scenarios. The calculations are made in Table 8, and the direct and indirect costs ${ }^{*}$ are plotted in Fig. 7.

\footnotetext{
${ }^{*}$ Defined as total costs less IDC.
} 


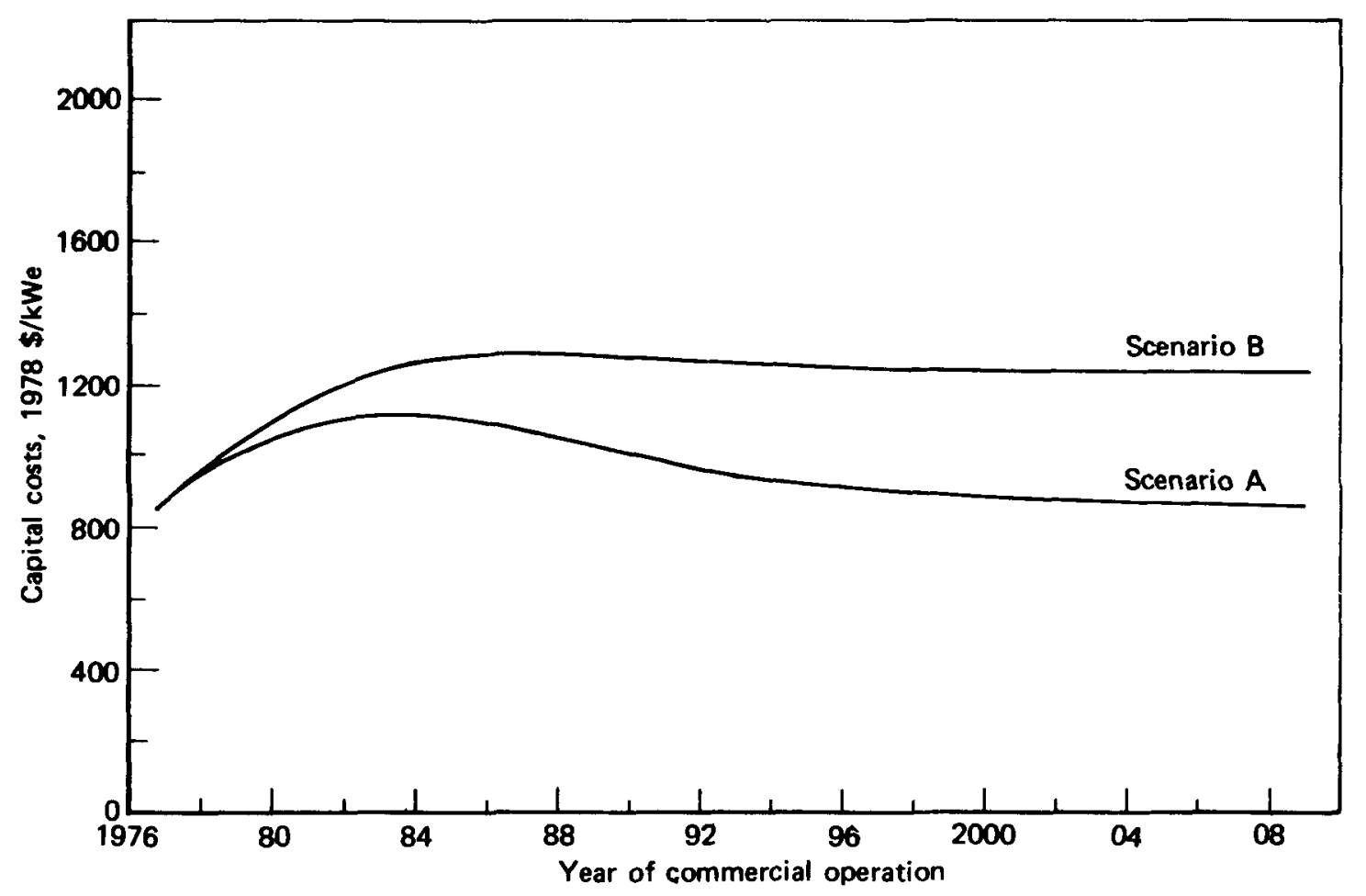

Fig. 6- LWR capital costs, IDC included

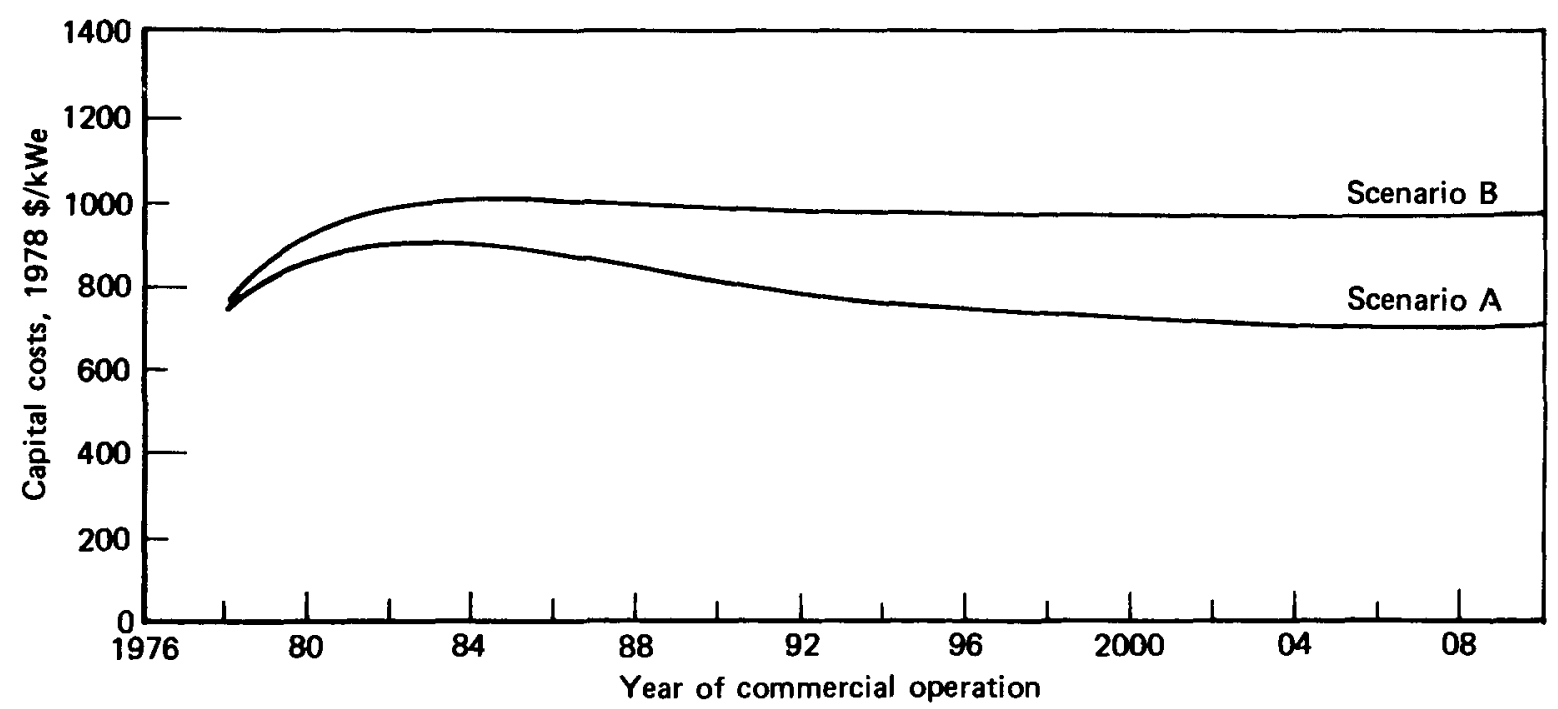

Fig. 7 - LWR capital costs, IDC excluded 
Table 8

CALCULATION OF IDC AND DIRECT PLUS INDIRECT COSTS

\begin{tabular}{|c|c|c|c|c|c|c|}
\hline $\begin{array}{c}\text { CPIS } \\
(\mathrm{Fig} \cdot 2)\end{array}$ & $\begin{array}{l}\text { Construction } \\
\text { Time, Months } \\
\text { (Fig. 2) }\end{array}$ & $\begin{array}{c}\text { IDC } \\
\text { Fraction } \\
\text { (Calculated) }\end{array}$ & $\begin{array}{l}\text { Date of } \\
\text { Commercial } \\
\text { Operation } \\
\text { (Fig. 3) }\end{array}$ & $\begin{array}{l}\text { Total } \\
\text { Cost } \\
\text { (Fig. 6) }\end{array}$ & $\begin{array}{c}\text { IDC } \\
(\$ 1978 \\
\text { per } k W e)\end{array}$ & $\begin{array}{c}\text { Direct Plus } \\
\text { Indirect Costs } \\
\text { (\$1978 per } \mathrm{kWe})\end{array}$ \\
\hline
\end{tabular}

Scenario A

\begin{tabular}{l|l|l|l|l|l|l}
\hline 1972 & 68 & 0.185 & 1978 & 930 & 170 & 760 \\
1974 & 72 & 0.194 & 1980 & 1060 & 210 & 850 \\
1976 & 74 & 0.198 & 1983 & 1100 & 220 & 880 \\
1978 & 74 & 0.198 & 1985 & 1100 & 220 & 880 \\
1980 & 74 & 0.198 & 1987 & 1070 & 210 & 860 \\
1982 & 73 & 0.195 & 1989 & 1040 & 200 & 840 \\
1984 & 72 & 0.194 & 1991 & 1000 & 190 & 310 \\
1986 & 71 & 0.191 & 1993 & 960 & 180 & 780 \\
1992 & 70 & 0.189 & 1998 & 900 & 170 & 730 \\
1999 & 69 & 0.187 & 2005 & 860 & 160 & 700 \\
2003 & 69 & 0.187 & 2009 & 860 & 160 & 700 \\
\hline
\end{tabular}

Scenario B

\begin{tabular}{l|l|l|l|l|l|l}
\hline 1972 & 68 & 0.185 & 1978 & 950 & 180 & 770 \\
1973 & 72 & 0.194 & 1979.4 & 1060 & 210 & 850 \\
1974 & 74 & 0.198 & 1980.6 & 1140 & 230 & 910 \\
1975 & 76 & 0.202 & 1982 & 1200 & 240 & 960 \\
1976 & 77.5 & 0.205 & 1983 & 1240 & 250 & 990 \\
1977 & 78.5 & 0.207 & 1984 & 1270 & 260 & 1000 \\
1978 & 79.5 & 0.209 & 1985 & 1280 & 270 & 1010 \\
1979 & 80 & 0.210 & 1986 & 1280 & 270 & 1010 \\
1983 & 80 & 0.210 & 1990 & 1260 & 260 & 1000 \\
1992 & 80 & 0.210 & 1999 & 1240 & 260 & 980 \\
1998 & 80 & 0.210 & 2005 & 1240 & 260 & 980 \\
2003 & 80 & 0.210 & 2010 & 1240 & 260 & 980 \\
\hline
\end{tabular}


IV. LMFBR COST SCENARIOS AND COST RATIOS

\section{CURRENT COST RATIO}

The $1977 \mathrm{GE}$ cost estimate of an LWR, provided in conjunction with the GE LMFBR design study, was $\$ 900$ per kWe, in 1978 dollars. Using the Rand methodology described in the previous sections, the direct plus indirect cost (excluding IDC) for an LWR starting construction in 1977 is $\$ 870$ per kWe for Scenario A and $\$ 1000$ per kWe for Scenario B; these estimates bracket the independent value of GE.

The costs given above do not include IDC. So long as the construction times for both types of plant are identical, the LMFBR/LWR cost ratio is not affected by the exclusion of IDC, since the same term will appear in numerator and denominator. If the LMFBR takes longer to construct, as some believe, the ratio will increase, depending on the construction time difference and prevailing interest rate.

Assuming equal construction times, the LMFBR costs shown in Table 4 , and using the value $\$ 900$ per kWe for the LWR, the "1977" LMFBR/LWR cost ratios are as shown in Table 9.

Table 9

LMFBR/LWR COST RATIO IN "1977"

\begin{tabular}{c|c|c|c|l}
\hline Manufacturer & Rand Estimate & Ratio & SSAI Estimate & Ratio \\
\hline AI & 1043 & 1.15 & 1105 & 1.23 \\
GE & 1495 & 1.61 & 1326 & 1.47 \\
Westinghouse & $863-1142$ & 1.27 & $969-1248$ & 1.39 \\
\hline
\end{tabular}

In Table 9 we use the higher Westinghouse figure, since the lower one is implausibly close to, or even lower than, the cost of the LWR being used. Rounding off, it appears that the LMFBR/LWR cost ratio at present lies in the range 1.2 to 1.6 , assuming equal construction times. If an LMFBR took 25 percent longer to build, this range would increase by about 5 percent, and would be 1.25 to 1.7 . The effects of differing construction times are discussed later in this section. 


\section{LMFBR CAPITAL COST SCENARIOS}

We will use the estimated capital cost ratios for 1977 from Table 9, the accompanying assumption that the ratio is obtained from the direct and indirect costs alone (IDC is excluded), and the assumption that the same ratio will apply to whatever LWR costs exist at the time the "fifth of kind" LMBR is built. This last assumption is based on the belief that whatever affects LWR costs will affect LMFBR costs as we11.

\section{Schedule of Commercial Operation}

The earliest date assumed for the LMFBR to enter commercial operation is 2002. The schedule of commercial operation is similar to that for LWR, and is taken from Ref. 5. The schedule appears in Table 10.

\section{LMFBR Scenario A}

A basis for examining probable future cost trends for LMFBR power plants is provided by the past and expected future costs of LWRs, as discussed in previous sections.

In the LWR Scenario A, the nuclear enterprise grows vigorously. Nuclear power attains a capacity of 200 GWe in 1990 and it captures a significant percentage of the market for new plants in the ensuing decade, attaining 400 GWe by 2000. Subsequent to 2000, we speculate that the growth rate of total generation declines to perhaps 3 percent per year, but if the nuclear capture rate increases, the total nuclear capacity in 2020 may be expected to reach 900 GWe out of a total of 2900 GWe.

In this projected environment, the reactor manufacturers constitute a vital industry, with several firms competing actively for a substantial market. Many plants- -30 to 50--are being built each year and costs have stabilized. Concomitantly, the regulatory climate and public acceptance have become favorable. Basic to this scenario, of course, is a satisfactory resolution of political issues, such as concerns about proliferation, waste management, etc., by institutional and technical advances.

Assuming such a favorable climate for an expanding nuclear enterprise, it is reasonable to expect that an LMFBR demonstration project 
Table 10

SCHEDULE OF LMFBRS IN COMERCIAL OPERATION

Year

2002

2003

2004

2005

2006

2007

2008

2009

2010

2011

2012

2013

2014

2015

2016

2017

2018
Cumulative

Number

1

2

3

4

4

4

4

4

6

8

11

16

22

30

41

50

54

will be initiated in the early 1980 s and will be operating around 1990 . Alternatively, intergovernment technical exchange agreements and commercial licensing arrangements could provide comparable experience from ongoing foreign LMFBR plant operation and technology development.

A satisfactory technological base for initial commercial LMFBRs will exist, under these premises, by about 1992, after perhaps two years of operation of the prototype large breeder reactor (PLBR) and more than 15 years of experience with similar foreign plants. Provided the capital costs of the LMFBR are acceptable, it is reasonable to believe that LMFBRs will begin to be ordered commercially after 1992, at a gradually increasing pace. Various rates of deployment of commercial breeder plants in the 1990 to 2000 time period can be defended.

One such pattern of growth is simply a repetition of the early history of LWR deployment, in the period 1960 to 1978. There, a sequence of about one order per year for several years was followed by a pause to reexamine earlier decisions, then a fairly rapid surge of 
additional orders. If we arbitrarily adopt this growth pattern, even though the logic for it appears unduly pessimistic considering the assumed favorable nuclear power environment, the number of LMFBRs coming into commercial operation subsequent to 2000 is as shown in Table 10 and Fig. 8, along with the number of LWRs assumed earlier.

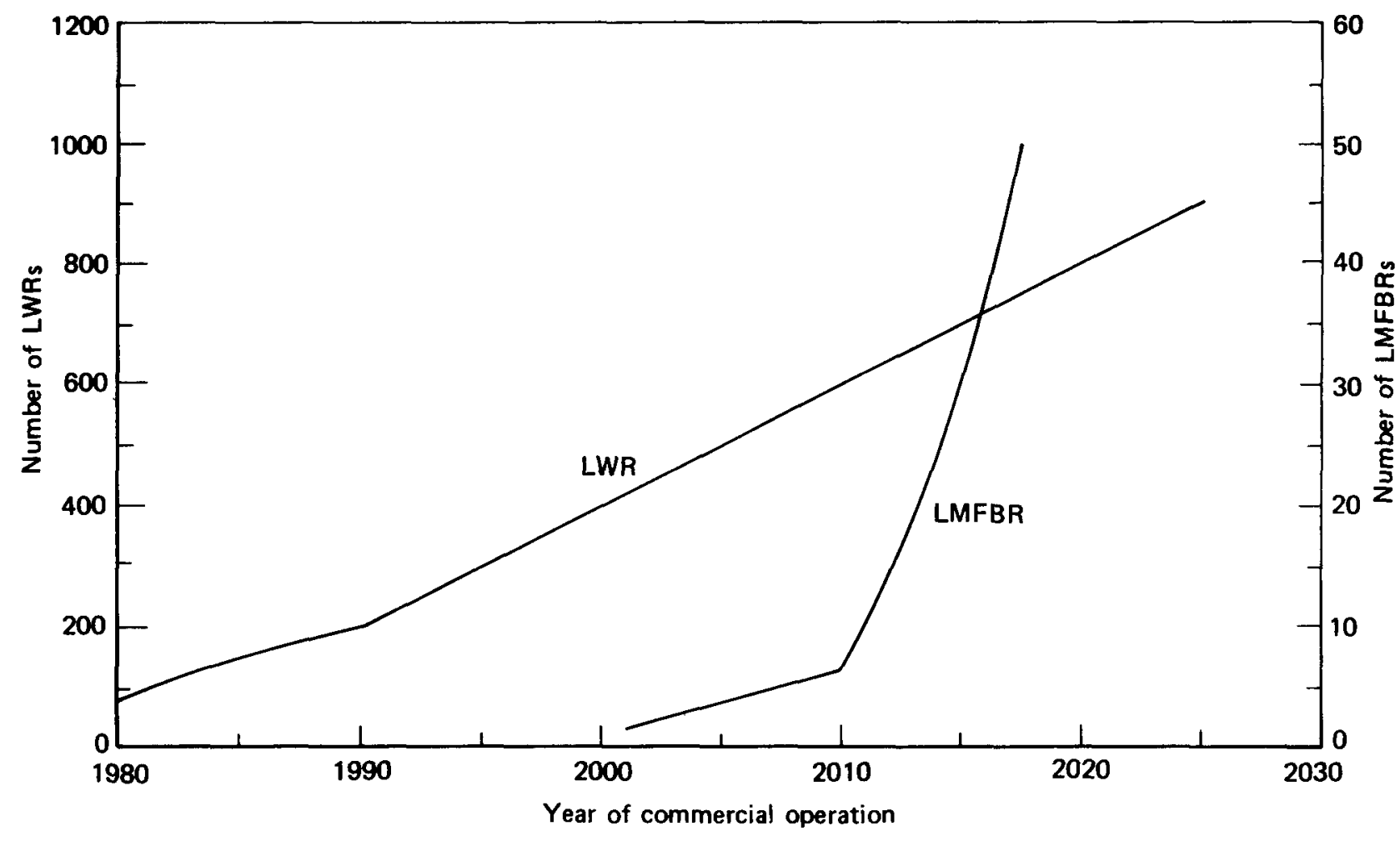

Fig. 8-Number of nuclear plants in commercial operation

The analysis of LMFBR "fifth of kind" and LWR cost estimates resulted in the cost ratios in Table 9. The ratio experienced with the first few of this family of LMFBRs, whose construction period will probably be longer than that of their LWR contemporaries, will 1ie toward the top of the range indicated, perhaps 1.6. By the time the fifth plant is built, in this scenario, we believe the ratio will have decreased. The total cost of the LWR, including IDC, has stabilized at about $\$ 860$ per $\mathrm{kWe}$; see Fig. 7.

A study of current designs suggests that substantial conservatism and generous contingency allowances have been included for many items, 
especially in the NSSS. It seems likely that, as designs are iterated and the basic configuration of the plant is changed from the present loop system to the probably preferable pool configuration, cost savings will accrue. With some degree of cautious optimism, assuming nearly equal construction times and a cost ratio of 1.4 , a cost differential of $\$ 340$ per kWe appears likely for the "fifth of kind" LMFBR. Unofficial comments on the French experience with Phenix and Super-Phenix support this point of view.

Assuming that three reactor manufacturers are competing for LMFBR sales, with one of them capturing 50 percent of the market, we observe from Fig. 8 that a plant coming on line in 2012 should be "fifth of kind," costing $\$ 1200$ per kWe. Thereafter, we should expect some benefits from learning, larger scale multiple manufacture, and possibly stretch capability inherent in the plant design.

The "balance-of-plant" (BOP) does not vary much between the LWR and LMFBR. Since, by 2012, many hundreds of LWRs will have been built, the benefits of learning will be small on the BOF portion, about twothirds of the LMFBR. Assuming a typical benefit from learning equal to the LWR experience, there would be a saving of 2.7 percent by 2014 , 5.4 percent by 2016, and about 8 percent by 2020. These LMFBR costs, declining slightly during the period 2012 to 2020, are shown in Fig. 9, which also repeats the LWR curve of Fig. 6 .

These curves suggest that the LMFBR cost will stabilize at a ratio of about 1.2 times LWR cost, but it is unlikely to go below that because of inherent differences, the intermediate heat transfer and the mechanized fuel handling systems being typical examples, between the two systems. Only if major changes from present concepts become acceptable, such as elimination of the intermediate heat transfer system or increasing reactor outlet temperature to a level permitting plant efficiencies of 40 percent or more, could the two system costs approach each other more closely.

It should be observed that the LMFBR cost trends projected here do not at all resemble the experience for the LWRs during the 1960 to 1980 period, when a precipitous rise occurred. The environment for LMFBR deployment we are assuming is favorable. Licensing issues will 


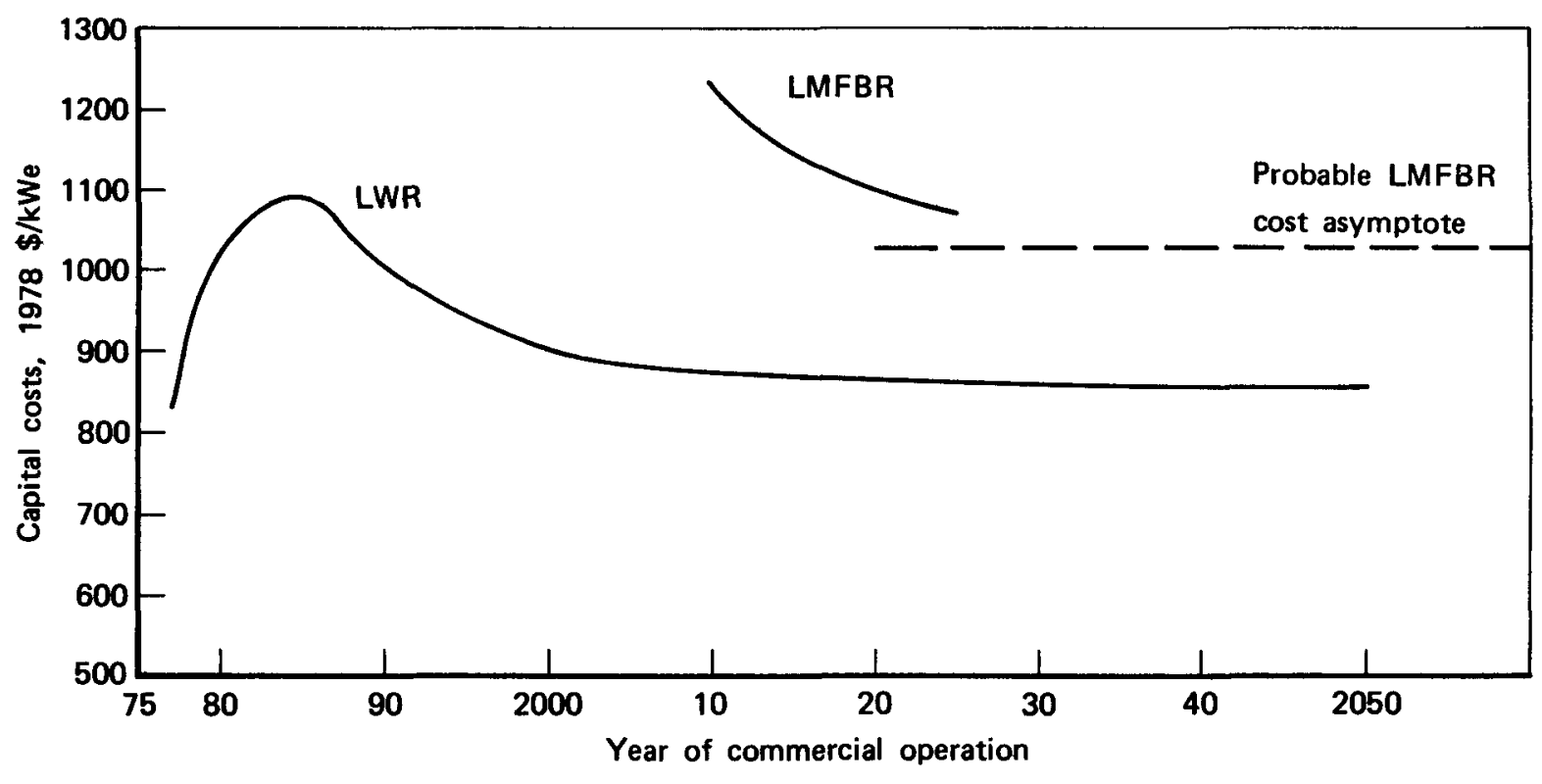

Fig. 9 - LMFBR and LWR cost trends for Scenario A, IDC included

have been identified and resolved during the PLBR phase preceding the commercial plants. The licensing delays and "ratcheting" which were experienced during the initial years of LWR deployment will not be repeated for the LMFBR, the regulatory process having become more stable. The plant designs and sizes will remain more standardized than was true for the LWRs, to permit truly multiple manufacture and lower indirect costs.

The cost behavior of this first family of LMFBRs, perhaps the first 50 deployed in a similar temporal pattern, appears unlikely to depend on when the system is actually adopted. If the PLBR and initial commercialization are delayed 10 years, the cost curve of Fig. 9 will simply be shifted to the right by that period. The additional R\&D information likely to accrue during the 10 year hiatus does not appear likely to produce significant, or even sma11, improvements in capita1 cost. The principal gains from an R\&D program would most likely be in fuel cycle costs. The major capital cost benefits arise from operating 
experience with prototype and pioneer plants; delays in starting these simply shift the program and the trend of plant costs onward in time.

\section{LMFBR Scenario B}

Based on the schedule in Table 10, four LMFBRs reach commercial operation by 2005 . We have not specifically examined what their capital costs might be, but it is reasonable to assume that costs were steadily reduced with each succeeding plant, and that the "fifth of kind" plant is the least costly of the first five. We then speculate that in the seven years between 2002 and 2009 serious questions arise regarding safety and security against diversion or sabotage. As a result of these questions and the attempts of regulatory authorities to deal with them, changes are made in the plant design that result in higher capital costs.

The list of changes that could increase capital costs could be sizable. In this scenario, no attempt is made to suggest what items would head the list. Typical items that might be considered are:

Safety items, to prevent loss of coolant and subsequent core melt. A core catcher and additional containment may be necessary.

Security items would include all types of physical security measures that might be taken to prevent sabotage at the plant.

Safeguards are actions that might be taken to deter proliferation; they might include the use of fuels which could require a higher capital cost plant.

Some of these items may be included in the earliest plants, and it should not be implied that plant designers were either unable or unwilling to address them. They are mentioned to illustrate areas of concern that are different from those pertaining to the LWR. Costs may increase because the measures taken may be later judged to be inadequate, or not sufficiently conservative--regardless of how conservative the initial design was thought to be. The cost increases hypothesized 
for the high cost scenario result from the continued concern of the regulatory authorities for ever greater assurance against possible malfunctions or accidents, and the engineering changes that ensue.

These concerns begin to take effect after the fifth plant has reached commercial operation. Costs begin to increase because of them, and are hypothesized to increase in a manner analogous to the LWR historical trend and the LWR high cost scenario, except that the rate of temporal cost increase is half that of the LWR. The choice of one-half is based on the assumption that the LMFBR has learned from the LWR experience and has integrated this learning into its design to the maximum extent possible. However, the LMFBR specific items discussed above still increase costs but at half the rate experienced for the LWR. Capital costs rise to the year 2019, at which point the temporal cost increases are just offset by cost learning. Then the cost 1earning effects take over and costs begin to decrease with increasing deployment of the LMFBR. This is shown in Fig. 10 .

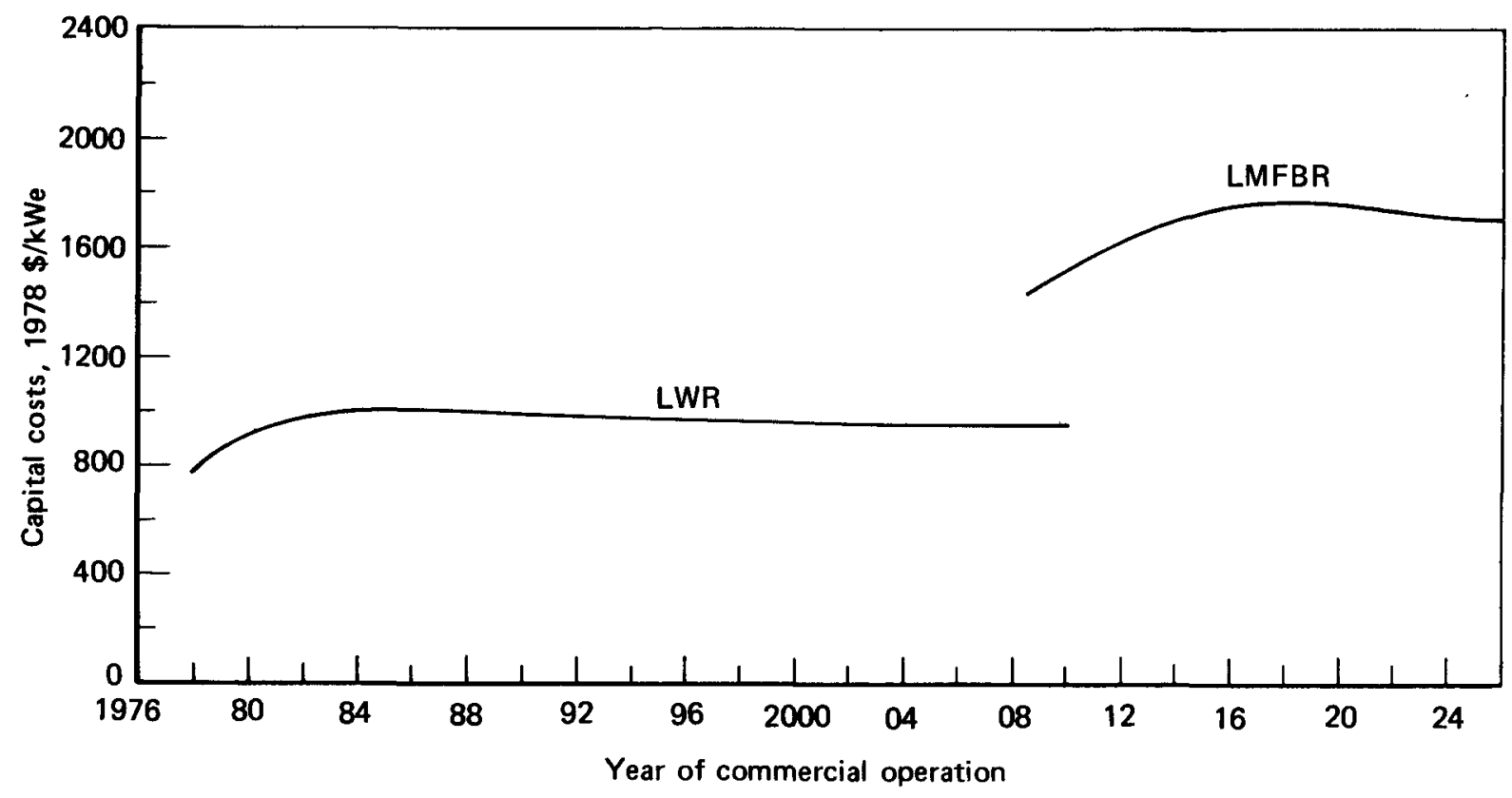

Fig. 10-Capital costs for Scenario B, IDC excluded 
From these data, capital cost ratios may be estimated for Scenario B both with and without IDC. From 2009 onward, the LWR direct and indirect costs are virtually constant at $\$ 980$ per $k W e$, and the cost ratio is simply a function of the LMFBR cost estimate. Construction time is a factor in the cost ratios, since if the LMFBR takes longer to build the IDC will be greater because of it. Using the 80 month average construction time for the LWR shown in Fig. 2, multipliers can be developed to adjust the ratio of direct and indirect costs for the effect of construction time differential. Some are shown in Table 11 for a reasonable range. (GE-Bechtel indicated that the construction time ratio might be 1.25. )

\section{Table 11}

MULTIPLIERS FOR DIFFERENTIAL CONSTRUCTION TIME

Ratio of LMFBR Constmetion Time to LWR Construction time

$\begin{array}{ll}1.0 & 1.0 \\ 1.1 & 1.02 \\ 1.2 & 1.04 \\ 1.3 & 1.06\end{array}$

Cost Ratio Multiplier

1.0

.04

1.06

Finally, using the LMFBR costs shown in Fig. 10 and the information in Table 11, we can generate the time-phased cost ratios and total capital costs for various estimated construction times. These appear in Table 12.

This scenario shows that under conditions of equal construction time for both the LWR and LMFBR, the cost ratio will rise from 1.50 to 1.82, and then taper off to about 1.76. Should the LMFBR take longer to construct, as is expected, the ratios will rise.

Direct plus indirect costs of the LMFBR start at $\$ 1460$ per kWe in 2009 for the "fifth of kind" plant, then rise due to the imposition of more stringent requirements to a peak of $\$ 1780$ per $\mathrm{kWe}$ in 2019 . They then slowly fall off to $\$ 1720$ per $k$ We in 2028. Interest during construction adds to these costs, bringing the total to $\$ 1850$ per $\mathrm{kWe}$ in 
Table 12

LWR AND LMFBR CAPITAL COSTS AND CAPITAL COST RATIOS FOR SCENARIO B

(in 1978 dollars per $\mathrm{kWe}$ )

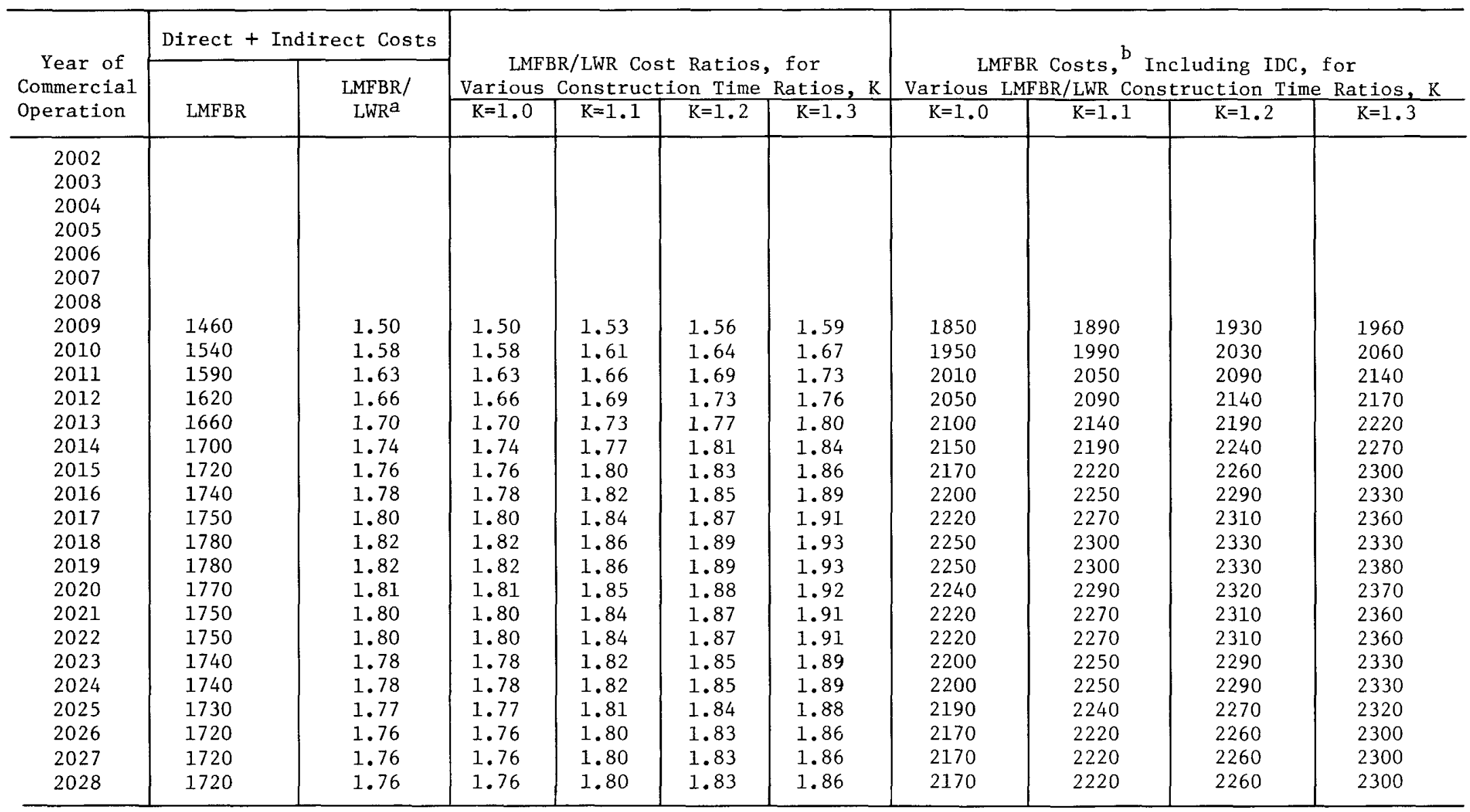

${ }^{a}$ Ratios are obtained by using a cost of $\$ 980$ for the LWR. This value is without IDC and is constant for all years.

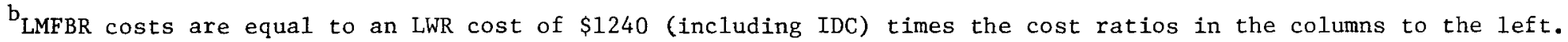


2009 , rising to $\$ 2250$ in 2018 , and trailing off to $\$ 2170$ in 2028 . If construction time is longer for the LMFBR, these estimates rise.

The increase in direct plus indirect costs in this scenario resulted from more stringent requirements concerning safety and sabotage. The actual amount attributed to these and additional requirements is the difference between the peak cost of $\$ 1780$ per $k W e$ and the "fifth of kind" cost of $\$ 1460$, or $\$ 320$ per $k W e$. For a 1000 MWe plant, this would represent $\$ 320$ million dollars. 


\section{TIMING OF INTRODUCTION OF LMFBR}

The scenarios described in this report are based on the first commercial LMFBR reaching commercial operation in 2002. Other scenarios could address the question of how costs would change if this date were delayed. Capital costs of the LMFBR could change if it were thought that the additional time available could be spent in R\&D activities that might lower the cost. They might also change as a result of changes in the costs of the LWR.

The scenarios have already assumed that the LMFBR will take advantage of all available technical knowledge, whether it originates in the LWR, in domestic LMFBR programs, or in foreign LMFBR programs. The state of this knowledge in 2002 will be such that waiting longer before introducing the LMFBR might have only a small effect on its initial capital costs, and probably no effect on its long run costs. LWR capital costs will decrease slightly after 2002 because of cost learning. The reduction is not large in either scenario, and in any event the LMFBR cost ratio will be the same, since this is one of the ground rules that was used. As a result, the cost ratios and the costs themselves would not be substantially different for scenarios in which the LMFBR deployment is delayed. 
VI. EFFECT OF VARIATIONS IN ASSUMPTIONS

In this section, we will examine each of the major assumptions, the range over which the values are relevant, and the likely effect on the scenarios.

\section{LMFBR-LWR COST DIFFERENCES}

Section II considered the derivation of capital cost ratios that were based on the estimated capital cost differences between the LMFBR and the LWR. These differences, as estimated by SSAI, varied between $\$ 205$ per $\mathrm{kWe}$ and $\$ 426$ per $\mathrm{kWe}$, not including IDC. Rand estimated a wider range, based on slightly different adjustments to the estimates, of $\$ 143$ per $\mathrm{kWe}$ to $\$ 595$ per $\mathrm{kWe}$. Using these latter values would make the capital cost ratios (subject to adjustment for IDC)

$$
\begin{gathered}
\frac{143+900}{900} \text { to } \frac{595+900}{900} \\
\text { or } \\
1.16 \text { to } 1.66
\end{gathered}
$$

An initial ratio of 1.16 is improbable, and should probably be dismissed. Scenario A implies that the inherent differences between the LMFBR and LWR would be unlikely to result in a cost ratio less than 1.2 without major changes from present concepts. Such changes were not contemplated for the LMFBRs in this study.

If the initial ratio were 1.66 instead of 1.5 , the LMFBR costs in Scenario $B$ would rise by about 11 percent, and the cost ratios that were estimated would increase by the difference between 1.66 and 1.5 ; i.e., by 0.16 .

INITIAL CAPITAL COST RATIOS

This subject has been partially covered above. The beginning cost ratios used in the study were 1.20 to 1.60 , and were derived without 
inclusion of IDC. If IDC were included, these ratios would increase. Assuming that the LMFBR would take 25 percent longer to construct, the beginning ratios would become 1.25 to 1.7 . The cost ratios estimated for Scenario A would increase by 0.05 and those for Scenario B by 0.1 .

\section{COST LEARNING}

The learning effect was maximized uniformly in both scenarios and for the LWR by assuming that the architect engineer employed constructed half of all the plants built. Relaxing this assumption somewhat would raise costs for both scenarios and for both the LMFBR and the LWR. For the LMFBR, learning was applied to only one-third of the plant cost, assuming that the BOP was generally similar enough to that of the LWR that little learning benefit would accrue to that portion of the LMFBR.

\section{COST GROWTH}

Assumptions about cost growth due to increased scope are the basis for the cost estimates. For the LWR, cost growth has been projected for both scenarios on bases that seem plausible. However, debate about plausibility may be academic, because the scenarios rely on the premise that the beginning cost ratio holds for whatever LWR costs happen to be at the time the "fifth of kind" LMFBR is deployed. Thus, varying the LWR cost scenarios will have little effect on the cost ratios. It would, of course, have a substantial effect on the absolute capital costs.

On the other hand, cost growth for the LMFBR relative to the LWR is the key factor in influencing the cost ratios. Scenario A forecasts no cost growth for the LMFBR, subsequent to the "fifth of kind" plant. Scenario $B$ suggests that the LMFBR costs (excluding IDC) will increase from about $\$ 1460$ per kWe to about $\$ 1720$ per kWe in 2028 , or about 18 percent, due to increased plant scope for reasons of safety, security, and safeguards.

INTEREST DURING CONSTRUCTION (IDC)

If the construction times for an LMFBR and an LWR are equal, the IDC does not enter into the cost ratio calculation. Since the LMFBR 
is more complex than the LWR, and since there is more construction work involved, the LMFBR time may exceed the LWR time. Scenario A has assumed that the construction times become equal for plants beyond the "fifth of kind." Any change to this assumption of equal construction time will increase LMFBR costs and increase the cost ratio. If the construction times differ by 25 percent, the cost ratios will increase by about 5 percent at a nominal IDC rate of 8 percent per year. Table 11 for Scenario $B$ shows how the LMFBR costs and cost ratios depend on the ratio of construction times.

\section{COMBINED EFFECTS}

Several of the above parameters could assume values that act in the same direction, and since some of the sensitivities are additive and others are multiplicative, general rules for estimating the net effects are not possible. Rather, the guidelines of Sec. VII can be used to estimate the net effects. 


\section{A SIMPLIFIED METHOD FOR ESTIMATING COST RATIOS}

The two scenarios used in this report may provoke curiosity on the part of a reader who may wish to estimate cost ratios for an alternative scenario. Some simple guidelines will help to make rough estimates.

1. Select a cost for an LWR that reaches commercial operation in 2009 .

2. Choose the initial LMFBR/LWR cost ratio. This initial ratio was suggested to be in the range of 1.2 to 1.6 in this study; other studies have suggested ranges of 1.25 to 1.75 .

3. Multiply the selected LWR cost by the initial capital cost ratio. This will give the estimated cost of the "fifth of kind" LMFBR.

4. Estimate the degree to which the LMFBR cost trajectory will be similar to that of the LWR' initial history. In terms of cost increases, use the following guide:

\section{Assumed cost growth beyond "fifth of kind"}

50 percent greater than LWR

25 percent greater than LWR

The same as LWR

75 percent as great as LWR

50 percent as great as LWR

25 percent as great as LWR

None

25 percent less than none

50 percent less than none

75 percent less than none
Add

Add

Add

Add

Add

Add

Add

Subtract

Subtract

Subtract

$\$ 1050$ per $k W e$
875 per $k W e$
700 per $k W e$
525 per $k W e$
350 per $k W e$
175 per $k W e$
0
175 per $k W e$
350 per $k W e$
525 per $k W e$

5. Add (or subtract) the amount estimated in Step 4 to the LMFBR cost estimated in Step 3. This yields the approximate 1ong run capita1 cost of the LMFBR, assuming equal LWR and LMFBR construction times.

6. Divide the LMFBR cost obtained in Step 5 by the LWR cost estimated in step one to obtain the LMFBR/LWR capital cost ratio, assuming equa1 construction time. 
7. Select a ratio of LMFBR/LWR construction time, and the appropriate LMFBR capital cost multiplier, from below.

$\begin{array}{cc}\text { LMFBR/LWR } & \text { Cost Ratio } \\ \text { Construction Time } & \text { Multiplier } \\ 1.0 & 1.0 \\ 1.1 & 1.02 \\ 1.2 & 1.04 \\ 1.3 & 1.06\end{array}$

8. Multiply the LMFBR/LWR cost ratio by the multiplier selected in step 7. This produces the final LMFBR/LWR cost ratio.

The above procedure neglects learning effects, which are not a dominant factor. If they are to be taken into account, assumptions must be made about both the LWR and LMFBR construction schedules and the number to be built by each architect engineer. Capital costs will decrease by about 8 percent for each doubling of the number of plants built by any single architect engineer.

An example of the use of the above estimating method follows:

1. Set LWR cost (in 1978 dollars) in $2009=\$ 1000$ per kWe.

2. Set initial LMFBR/LWR cost ratio $=1.4$.

3. "Fifth of kind" LMFBR cost $=\$ 1000 \times 1.4=\$ 1400$ per $\mathrm{kWe}$.

4. Set LMFBR cost history equal to "25 percent as great as LWR cost history." (Add $\$ 175$ per kWe.)

5. $\$ 1400+175=\$ 1575=1$ long run LMFBR cost, at equal construction time with LWR.

6. LMFBR/LWR cost ratio $=\frac{\$ 1575}{\$ 1000}=1.6$.

7. Set LMFBR/LWR construction time $=1.1$. Cost ratio multiplier equals 1.02 .

8. $1.6 \times 1.02=1.6=$ final cost ratio. 


\section{.}

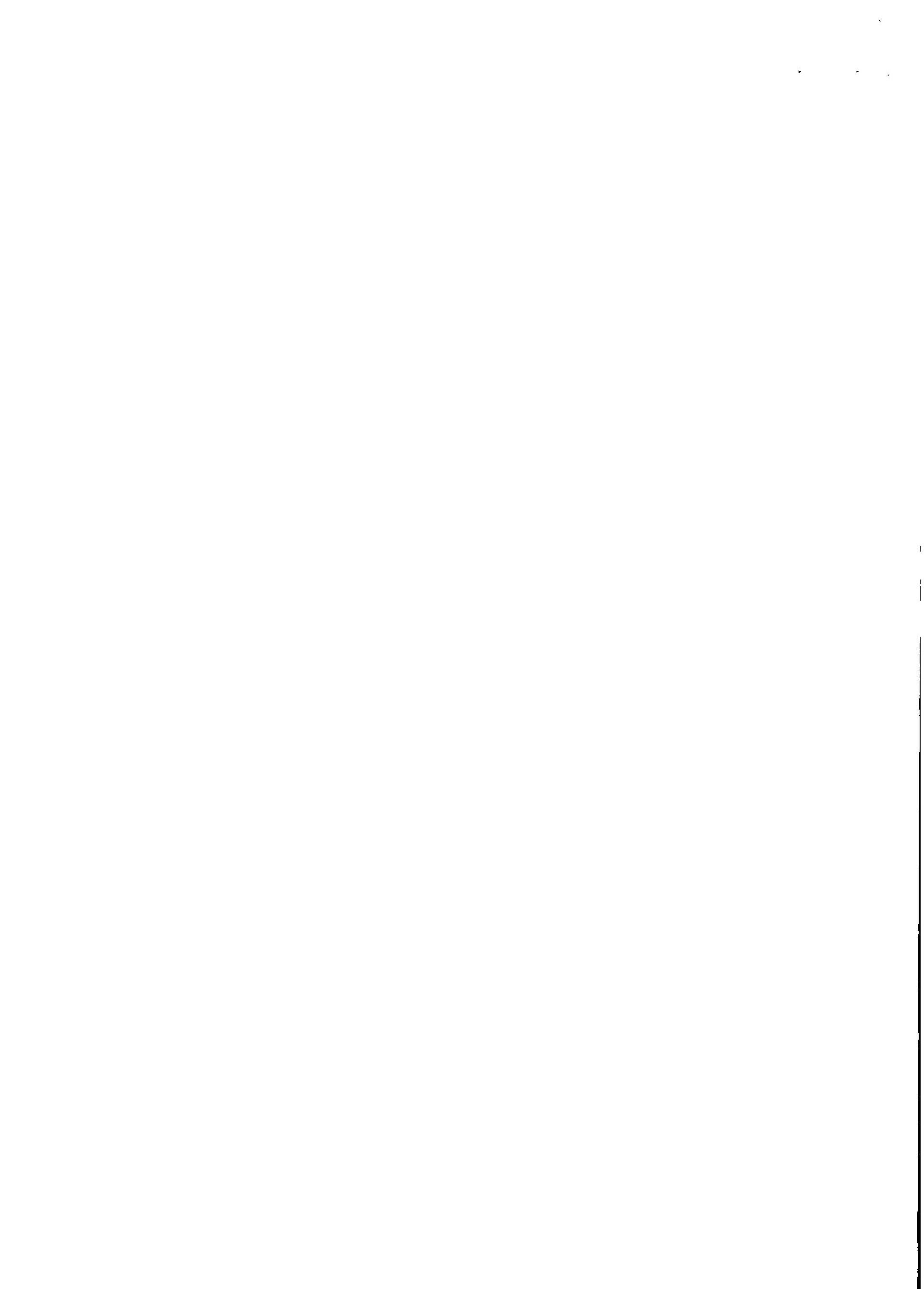




\section{REFERENCES}

1. Liquid Metal Fast Breeder Reactor Conceptual Design, Atomics International and Burns and Roe, FBR-77-3, May 1977.

2. Prototype Large Breeder Reactor Conceptual Design, General Electric Co. and Bechte1 Corporation, BTR-8, June 1977.

3. Prototype Large Breeder Reactor, Phase II, Final Report, Westinghouse Advanced Reactor Division, November 1977.

4. Mooz, W. E., Cost Analysis of Light Water Reactor Plants, The Rand Corporation, R-2304-DOE, June 1978 .

5. U.S. Central Station Nuclear Electric Generating Units: Significant MiZestones, U.S. Department of Energy, Division of Nuclear Development, DOE/ET-0030/4(78), 1978. 


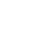

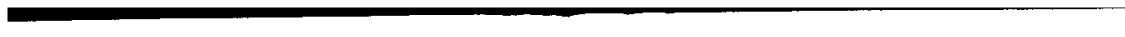

.

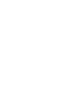


$-45-$

Appendix

A SUMMARY REVIEW OF LMFBR/LWR CAPITAL COSTS

Prepared by

Southern Science Applications, Inc. Dunedin, Florida 


\section{INTRODUCTION}

Plant capital costs are extremely important in the overall assessment and comparison of alternative electric power generating systems. For systems and concepts not yet fully developed, planning for the future requires that capital cost estimates be prepared, evaluated, and reviewed under various sets of ground rules and from different perspectives.

Southern Science Applications, Inc., under contract to The Rand Corporation, has performed a summary review of capital cost estimates for commercial liquid metal fast breeder reactor (LMFBR) plants and has compared these costs to the capital costs for light water reactor (LWR) plants. This work was undertaken in support of a study by The Rand Corporation that covers a hypothesized range of LMFBR/LWR costs.

The Southern Science review of capital cost data supplied to Rand by Atomics International, General Electric, and Westinghouse included evaluations of the overall completeness of the supplied data, estimations of appropriate adjustments to the data, and comparisons of the costs to base LWR costs.

The following section of this report is a summary of the results of the work. Section III provides engineering reviews of the plant designs, presented in a manner that emphasizes the differences in design that affect capital costs. Section IV contains specific reviews of the data supplied by the various vendors, while concluding remarks are given in Section $V$. 


\section{SUMMARY}

An overall review of specific capital cost estimates for commercial LMFBR plants has been performed. The estimates were made by Atomics International (AI), General Electric (GE) and Westinghouse (W) and supplied to Southern Science by The Rand Corporation. An engineering assessment of the LMFBR plant designs was initially performed that emphasized the differences from LWR plant designs. The LMFBR plants were considered as fifth-of-a-kind designs and compared to a fully developed commercial LWR. The assessment indicated the potential for significant differences in costs compared to LWR costs for the required LMFBR structures and facilities. This difference is expected due to the larger, dual containment and separate steam generator buildings for the LMFBR. Major cost differences are also expected for the reactor plant equipment of the LMFBR compared to the LWR. This is due to a number of items noted in Section III, including the Targer reactor vessel, presence of an intermediate loop and associated piping and components, and more complex steam generators for the LMFBR. Some LMFBR balance-of-plant (BOP) structures, systems and components could have costs comparable to an LWR design.

Capital cost estimates associated with the LMFBR designs were reviewed and compared to a base LWR cost. Cost estimates for the AI, GE and W plant designs, direct plus indirect costs only, were $\$ 984.3 \mathrm{M}, \$ 1154$. $1 \mathrm{M}$ and $\$ 863 \mathrm{M}$ to $\$ 1142 \mathrm{M}$, respectively. ${ }^{\star}$ A base cost of $\$ 770^{\star \star}$ for a $900 \mathrm{MW}(\mathrm{e})$ LWR (1977) was used. Review of the LMFBR data indicated that major cost elements had been

\footnotetext{
* The AI estimate is for a $1000 \mathrm{Mw}(\mathrm{e})$ plant in 1977 dollars, the GE estimate is for a $900 \mathrm{Mw}(\mathrm{e})$ plant in 1977 dollars. The range of costs for the $\mathrm{W}$ estimate is for a $1000 \mathrm{Mw}(\mathrm{e})$ plant in 1978 dollars. The letter "M" is used to denote millions.

${ }^{* *}$ This is the value estimated by GE. See p. 11 .
} 
addressed, although it could be postulated that some items were omitted. There was a lack of evidence that some 1and, structures, and waste treatment cost elements were covered in the estimates, so independent estimates were made to adjust the cost data. Adjustments of $\$ 22 \mathrm{M}, \$ 22 \mathrm{M}$ and $\$ 45 \mathrm{M}$ to $\$ 58 \mathrm{M}$ were made to the $A I, G E$ and $\underline{W}$ estimates, respectively. These adjustments did not yield a significant change in the basic capital cost data.

Comparing the LMFBR capital costs to the LWR costs corrected to an equal size and time basis yields the following ratios for both the unadjusted and adjusted estimates.

LMFBR/LWR Ratio
Unadjusted
Adjusted
$1.21 \quad 1.50 \quad 1.01-1.34$
$1.24 \quad 1.53 \quad 1.07-1.41$

AI GE $\quad \underline{W}$

The low range of the $\underline{W}$ data is judged to be unrealistically low and the remainder of the estimates appear credible considering the differences in the plant designs themselves. 


\section{ENGINEERING ASSESSMENT OF LMFBR/LWR CAPITAL COST ELEMENTS}

An intercomparison of commercial LMFBR and LWR plant designs was performed to identify cost elements that would be expected to yield significant differences in capital costs. To allow this combined technical/economic evaluation, an engineering assessment of the plant designs was performed using the cost account categories of the CONCEPT code. (1) The engineering design information for the AI, GE and W LMFBR plants is based on descriptions developed for the Prototype Large Breeder Reactor (PLBR) project. (2) Design information for LWR plants was obtained from typical safety analysis reports. $(3,4)$ The following paragraphs indicate the capital cost category and the engineering design differences expected to yield different capital costs within that category.

\section{A. Land and Land Rights}

No significant differences are foreseen between the LMFBR plant and LWR plant for this category. The exclusion area is expected to be the same for the two plants once the LMFBR reaches commercial status.

\section{B. Structures and Facilities}

Differences in plant layout would affect this cost element and several differences in LMFBR and LWR plant layout requirements are noted. The LMFBR designs require larger containments (20 to 50 percent larger diameter) and a11 incorporate a separate confinement structure. Some of the current generation of BWRs are also being built with a free standing steel containment and a separate confinement structure, but the cost of this is not in the current LWR cost estimates. The LMFBR containment design pressures are 3-10 psig as compared to approximately 15-20 psig for LWR containments.

The LMFBR layouts call for steam generator buildings which are not required for the LWR plants. The PWR steam generators are inside the 
containment and the comparable situation is the placement of the intermediate heat exchangers within the LMFBR containments.

The LMFBR plant layouts do not appear to provide for an administrative building, which is typically included in LWR costs.

The LMFBR containment and steam generator buildings will have to provide for sealed and inerted cells for much of the auxiliary equipment and piping runs that carry the sodium coolant. All of these piping galleries and cells will be steel lined to prevent molten sodium interaction with the concrete. These requirements introduce additional complexity into the plant layout for an LMFBR as compared to an LWR.

\section{Reactor Plant Equipment}

Engineering judgment has been exercised to provide a simple but meaningful intercomparison of the reactor systems. Obviously, almost every component requires different design criteria and materials when comparing an LMFBR to an LWR.

Both concepts have in common a loop-type primary coolant system to remove heat from a core consisting of fuel pins held in fuel subassemblies. The LMFBR has the added equipment cost represented by an intermediate heat transfer loop which requires additional piping, heat exchangers of approximately twothirds steam generator size, and intermediate pumps equal in size to primary coolant pumps.

The LMFBR is a low pressure system, but the mechanical design criteria are nonetheless challenging because of thermal shock potential due to the high thermal conductivity of the molten sodium. The vessel and primary coolant system must be designed to withstand a high transitory stress caused by rapid sodium vaporization in the core and the intermediate coolant system must be able to withstand a high stress loading from an energetic steam/sodium chemical interaction. 
All of the sodium-containing components are constructed entirely of stainless steel in the LMFBR as compared to stainless steel lining in LWR systems.

The LMFBR coolant system is constructed on the guard vessel principle. A rupture any place in the primary system is contained in either the stee 1 guard vessel around the reactor vessel or in guard pipes surrounding the primary cold leg piping. The volume of these guard vessels is limited so that the amount of sodium lost is not sufficient to uncover the core.

The effective core diameter of the LMFBR is approximately twice that of an LWR due to blanket subassemblies and the reflector/shield region. The reactor vessel of an LMFBR has approximately three times the diameter and 30 percent greater height than a PWR reactor vessel. However, the wall thickness of the LMFBR averages three (3) inches compared to eight (8) inches for a PWR. The primary coolant piping is approximately 20 percent greater in diameter than a PWR, but has a smaller wall thickness.

The refueling system for the LMFBR is more complicated than an LWR. This can be appreciated when one realizes that refueling an LWR can be a visual operation (looking down onto the flooded core) as opposed to refueling the LMFBR by remote equipment underneath the reactor vesse t head in an opaque coolant. The LMFBR fuel storage facility will also represent a larger investment than the LWR spent fuel pool because of the need for sodium cooling and blanket gas.

The cover gas in the coolant loops will represent an added investment, but this may be roughly matched by the investment in off-gas control required at LWR plants.

Sodium purity monitoring and cleanup systems will be required in the LMFBR, but this investment may be offest by the lack of the chemical and volume control system required for LWRs. 
The LMFBRs will require heat tracing on all of the sodium piping and extensive sodium leak detection equipment tied into the plant control system. The cost of these items is partially offset by a reduction in piping restraints required as a result of the absence of blowdown reaction forces on the piping.

The comparison of engineered safeguards systems indicates a diversity of designs for BWR, PWR, and different LMFBR concepts. However, all have to remove approximately the same time-dependent decay heat loading. The LWR systems have diverse coolant injection pumps, residual heat removal heat exchangers, ultimate cooling towers, ultimate heat sinks, and containment cooling systems. The LMFBR concepts employ additional steam generator feedwater backup and independent NaK loops with pumps rejecting heat through air heat exchangers. The LMFBR engineered safeguards systems are not judged to add a significant cost differential.

The steam generators for the LMFBR concepts will have to meet higher design and manufacturing standards in order to preclude a water-to-sodium leak that will result in an energetic chemical reaction. Some of the LMFBR concepts call for duplex tubes and double tube sheets. These stringent requirements will mean additional cost for these LMFBR components.

\section{Turbine Plant Equipment}

No significant difference is expected in capital cost associated with this category with the exception of the turbine-generator. Cost differentials between the $1800 \mathrm{rpm}$ (saturated) and the $3600 \mathrm{rpm}$ (superheated) systems are controversial. Since one of the LMFBR concepts also specifies a saturated steam cycle, no cost differential is assumed between LWR and LMFBR plants.

\section{E. Electric Plant Equipment}

Two of the LMFBR concepts identify three 100-percent-capacity diesel generators and the third concept calls for two 100-percent-capacity diesel generators plus two 100-percent-capacity gas generators. These represent approximately one extra diesel generator in excess of the LWR cost estimates. 
IV. CRITIQUE OF LMFBR CAPITAL COST DATA AND COMPARISON TO LWR COSTS

Estimates for commercial LMFBR plant capital costs made by AI, GE and W have been supplied by The Rand Corporation and are summarized in Table I through Table IV. This data was transmitted and identified as three data sets, $A, B$, and $C,{ }^{(5)}$ and that convention is also used in this report. Data Set $A$ corresponds to the AI design and Data Set B corresponds to the GE design. The Westinghouse estimate of Data Set $C$ originally contained a range of costs for the various elements and has subsequently been separated into two data sets, $\mathrm{C} 1$ and $\mathrm{C2}$, corresponding to the low and high values of the range, respectively.

As utilized in the engineering assessment discussed in Section III, the capital cost accounting structure of the CONCEPT code has been used to facilitate review of the data base. All data sets were converted into this structure. The varying levels of detail, or lack thereof, are more easily accommodated for comparative purposes by this structure. As appropriate, details of the data sets were combined into appropriate subaccounts consistent with the CONCEPT structure and similar accounting guidelines.

Table $V$ presents the four LMFBR capital cost data sets in the CONCEPT account structure. Account numbers and subaccount numbers have been used to identify the various cost elements. Accounts $20,21,22,23,24$ and 25 present the direct costs and accounts 91,92 and 93 present the indirect costs as obtained from reformatting the data from Tables I-IV. Costs are itemized by subaccounts as detail allowed. For Data Set A, no balance-ofplant detail was available.

The presentation of the LMFBR capital cost data as provided by Table $V$ lends itself to a critique of the cost estimates. One-to-one comparisons appear easy to perform and blanks appear quite obvious. However, a certain amount of caution is warranted. The data sets represent separate designs, or ranges of costs for a given design, so some significant differences are expected. Also, the tabulated data was taken from data sets with varying 
levels of detail, with different utilization of contingencies and "other" categories and with slightly different time bases for the costs. For some questions, then, the raw data warrants the benefit of a doubt. The annotations presented on Table $V$ refer to notes or adjustments that attempt to consider these factors.

As an initial assessment, the capital cost data was reviewed for possible omissions. The numerous blanks in several of the accounts suggest several omissions, but further review suggests that actual omissions are likely to yield only small relative cost adjustments. As noted in Table $V$, certain land costs, structures costs and waste treatment costs and other elements were assumed omitted and appropriate adjustments were made.

Whether a cost element was actually omitted or was covered elsewhere was highly judgmental. For those items that were assumed omitted, independent estimates were made and adjustments indicated in the table. The estimated adjustments (approximate in nature) were based on intercomparison of the LMFBR data, LWR data (7), engineering judgment and significance to the overa 11 plant cost. Considering the magnitude of the final adjustments, the cost associated with any omissions in the basic data is of less consequence than the cost differences that could actually exist due to differences in the LMFBR designs. The potential value of omissions is also felt to be within the accuracy or contingencies actually present in the estimates themselves.

LMFBR capital costs presented in Table $V$ are also compared to LWR costs. A reference capital cost for a $900 \mathrm{Mw}(\mathrm{e})$ LWR of 770 million dollars (January 1977) was provided by Rand. (8) This cost is direct plus indirect only and includes $\$ 95 \mathrm{M}$ for NSSS and $\$ 675 \mathrm{M}$ for balance-of-plant. Values on comparable power level and time bases as the LMFBR estimates have been obtained by scaling $(8,9)$ and given in Table $V$ for a hypothetical cost comparison. Relative cost comparisons between the LMFBR costs and the LWR data are presented. 
Table I LMFBR CAPITAL COST DATA SET A

Fifth-of-a-Kind $1000 \mathrm{MW}(\mathrm{e})$ LMFBR Costs

(\$ Militions, 1977)

NSSS - Major Items

NSSS - Auxiliary Items

Reactor Vessel

Guard Vesse 1

Reactor Internals

Deck and Plugs

Control Rods

Fuel Handling Systems

IHX

Pumps

PHTS, IHTS

Decay Heat Removal Systems

Steam Generators

$\mathrm{Na}$ Auxiliary Systems

Subtotal

NSSS Summary

Major Items

Auxiliary Items

NSSS Total

$\begin{array}{r}34 \\ 7 \\ 30 \\ 50 \\ 5 \\ 28 \\ 34 \\ 49 \\ 19 \\ 12 \\ 113 \\ 9 \\ \hline 390\end{array}$

390

78.9

468.9
$\mathrm{Na}$ Piping Preheat and Control

Cover Gas and Pressurizing Systems

Cavity Gas Cool Systems

Auxiliary Cooling System

Coolant Sampling Sys tems

Maintenance Systems

$\mathrm{Na}$ Fire Protection Systems

Rad Monitoring Systems

Fedal

Flux Monitoring Systems

Plant Protection System

Plant Control Systems

Console and Data Handling

Process I\&C

$\mathrm{Na}$ Inventory

Subtotal

Plant Summary

Nuclear Steam Supply System

468.9

365.4

834.3

Total Direct

150

Indirect

984.3

Total Plant

Contingency (included in above)

DATA SET A TOTAL
8.9

6.7

2.9

11.6

2.6

0.6

1.6

1.8

2.8

3.1

2.6

18.7

9.0

78.9 
Table II LMFBR CAPITAL COST DATA SET B

Fifth-of-a-Kind 900 Mw(e) Net LMFBR Costs

(\$ Mitlions, 1977)

Nuclear Steam Supply System

Reactor Equipment

Ma in Heat Transfer and Transport System

Safeguards Cooling System

Nuclear Fuel Handling

Other Reactor Plant Equipment

Instrumentation and Control

Engineering

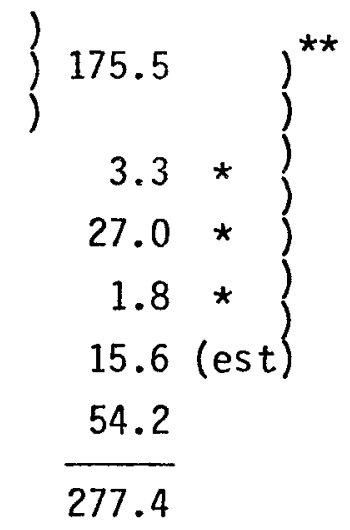

Subtotal

Balance-of-Plant

Site Improvements \& Facilities

9.6

Reactor Containment Building

81.8

Steam Generator/Pracs Bidg.

24.3

Turbine Building

20.6

Reactor Service Building

13.2

Miscellaneous Buildings

19.0

Reactor Plant Equipment

86.4

Turbine Plant Equipment

124.1

Electric Plant Equipment

62.9

Miscellaneous Plant Equipment

15.6

Field Distributable Costs

142.6

Engineering \& Home Office

115.0

Subtotal

715.1

Total Plant

992.5

Contingencies

161.6

DATA SET B TOTAL

1154.1

\footnotetext{
* Same as 1st and 20th of a kind **

NSSS Equipment Total $=223.2$
} 
Table III LMFBR CAPITAL COST DATA SET CI

Fifth-of-a-Kind $1000 \mathrm{MW}(\mathrm{e})$ LMFBR Costs

( $\$$ Militions, 1978)

NSSS Components

Balance-of-Plant

Reactor Vesse1

Reactor Head

Other Reactor Internals

\& Enclosure Equipment

Primary Pumps

Primary Pipe, Hangers,

Snubbers, Elbows

Other PHTS Equipment

Intermediate Pumps

Intermediate Pipes, Hangers,

Snubbers, Elbows

Intermediate Heat Exchangers

other IHTS Equipment

Steam Generators

other S/G Equipment

Fuel Handling and Storage Equipment

NSSS Instrumentation, Control, Monitoring

Auxiliary \& Miscellaneous Equipment NSSS Tota1

\section{Plant Summary}

NSSS $\quad 475$

BOP $\quad 388$
Turbine-Generator System

Turbine-Generator

Feedwater System

Condensing System

Cooling Tower (wet)

Circulating Water

Main Steam Piping and Restraints

Instrumentation and Control

Total Turbine-Generator System

Buildings and Structures

Containment

Steam Generator

Turbine Generator

Auxiliary Buildings

Total Buildings and Structures

Electrical Plant

Switchgear 3

Station Service 13

Switchboards

Power and Control Wiring

Structures

Protective Equipment

Total Electrical Plant

Land and Yardwork

Indirect Costs (Engineering Services,

Site Construction, Owner, and Other Costs) 120

Contingency on BOP 
Table IV LMFBR CAPITAL COST DATA SET C2 Fifth-of-a-Kind $1000 \mathrm{MW}(\mathrm{e})$ LMFBR Costs

(\$Millions, 1978)

\section{NSSS Components}

Balance-of-Plant

Reactor Vesse 1

Reactor Head

Other Reactor Internals

\& Enclosure Equipment

Primary Pumps

Primary Pipe, Hangers,

Snubbers, Elbows

other PHTS Equipment

Intermediate Pumps

Intermediate Pipes, Hangers, Snubbers, Elbows

Intermediate Heat Exchangers

other IHTS Equipment

Steam Generators

Other S/G Equipment

Fuel Handling and Storage Equipment

NSSS Instrumentation, Control, Monitoring

Auxiliary \& Miscellaneous Equipment

NSSS Total

Plant Summary

NSSS $\quad 600$

BOP 542
38

25

90

18

9

27

12

17

42

26

72

21

95

25

83

600

DATA SET C2 TOTAL

1142

Turbine-Generator System

Turbine-Generator

Feedwater System

Condensing System

Cooling Tower (wet)

Circulating Water

Main Steam Piping and Restraints

Instrumentation and Control

Total Turbine-Generator Sys tem

Buildings and Structures

Containment

Steam Generator

Turbine Generator

Auxiliary Buildings

Total Building and Structures

47

10

8

25
5

8

2

105

Electrical Plant

Switchgear

Station Service

Switchboards

Power and Control Wiring

Structures

Protective Equipment

Total Electrical Plant

Land and Yardwork

Indirect Costs (Engineering Services, Site Construction, Owner, and Other Costs) 160

Contingency on BOP

BOP Total 
$-60-$

Table $V$ LMFBR CAPITAL COST EVALUATION BY CONCEPT COST ANALYSIS ACCOUNT STRUCTURE

ACCOUNT

NUMBER

20

21

211

212

213

214

215

216

217

218

22

221

222

223

224

225

226

227

23

231

232

233

234

235

236
ACCOUNT TITLE

LAND AND LAND RIGHTS

STRUCTURES \& FACILITIES

Site Improvements \& Facilities

Feactor Building ${ }^{e}$

Turbine Building

Intake \& Discharge Struc.

Reactor Auxiliaries BIdg.

Radioactive Waste Bldg. 9

Fuel Storage Bidg.

other

REACTOR PLANT EQUIPMENT

Reactor Equipment

Main Heat Transfer and Transport Systems

Safeguards Cooling Systems

Radioactive Waste Treatment ${ }^{n}$ and Disposa?

Nuclear Fuel Handling \& Storage Systems

Other Reactor Plant Equip.

Instrumentation \& Control

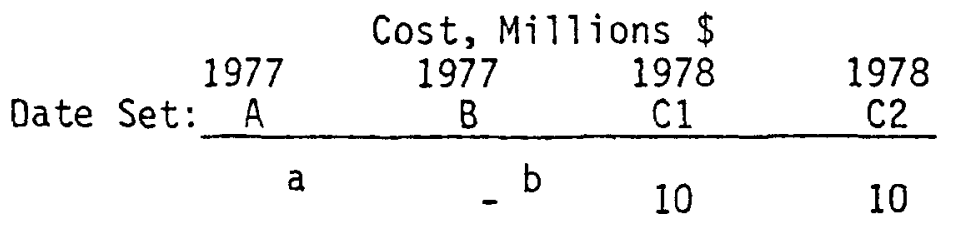

c

\begin{tabular}{|c|c|c|c|}
\hline & 106.1 & 57 & 110 \\
\hline & 20.6 & 33 & 40 \\
\hline & - & - & - \\
\hline & 13.2 & 12 & 14 \\
\hline & - & - & - \\
\hline & $-h$ & $-i$ & $-i$ \\
\hline & 19.0 & $-j$ & $-j$ \\
\hline $\bar{c}$ & 168.5 & 102 & 164 \\
\hline
\end{tabular}

126

$175.5^{k}$

125

153

223.9

12

$3.3^{1}$

188

244

- in

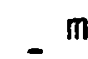

28

27.0

80

95

47.8

88.2

62

83

$\frac{31.2}{468.9} \quad \frac{15.6}{309.6}$

$\frac{20}{475}$

$\frac{25}{600}$

TURBINE PLANT EQUIPMENT

Turbine-Generators

Heat Removal Systems

Condensing Systems

Feed Heating System

Other Turbine Plant Equip.

Instrumentation \& Control

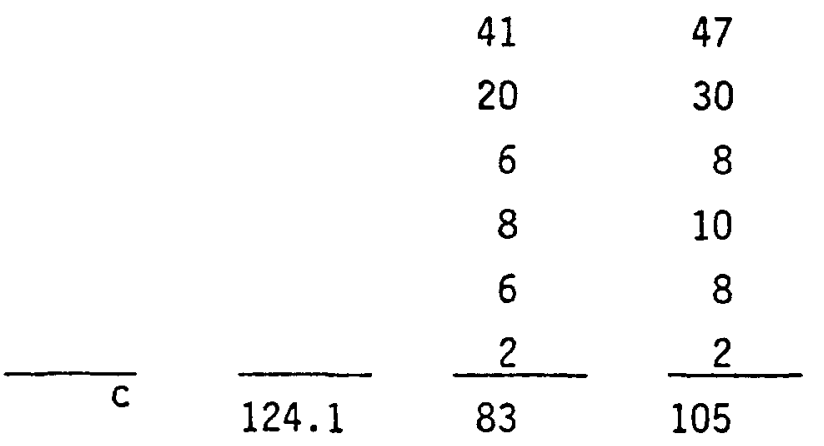


Table $V$ LMFBR CAPITAL COST EVALUATION BY CONCEPT COST ANALYSIS ACCOUNT STRUCTURE (continued)

ACCOUNT

NUMBER

24

241

242

243

244

245

246

25 MISCELLANEOUS PLANT EQUIP

91 CONSTRUCTION FACILITIES, EQUIPMENT, AND SERVICES

92 ENGINEERING \& CONSTRUCTION

MANAGEMENT SERVICES

93 OTHER COSTS

Data Set A BOP

CONT INGENCIES

LMFBR UNADJUSTED TOTAL

NET ADJUSTMENT

LMFBR ADJUSTED TOTAL

LWR COMPARABLE COST $^{t}$

LMFBR/LWR RATIO

UNADJUSTED

ADJUSTED

LMFBR-LWR DIFFERENTIAL, Millions \$

UNADJUSTED

ADJUSTED

Date Set: \begin{tabular}{cccc} 
& \multicolumn{4}{c}{ Cost, Millions \$ } \\
A & 1977 & 1978 & 1978 \\
\hline
\end{tabular}

\begin{tabular}{|c|c|c|c|c|c|}
\hline & & & 3 & & 3 \\
\hline & & & 13 & & 13 \\
\hline & & & 1 & & 1 \\
\hline & & & 1 & & 1 \\
\hline & & & 16 & & 16 \\
\hline & & & 20 & & 20 \\
\hline & $c$ & 62.9 & 54 & & 54 \\
\hline & $c$ & 15.6 & & ( & $-c$ \\
\hline 150 & $p$ & 142.6 & 120 & $p$ & 160 \\
\hline & $p$ & 169.2 & & 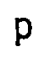 & F \\
\hline & $p$ & $-\subseteq$ & & $p$ & f \\
\hline
\end{tabular}

365.4

$\begin{array}{cccc}\frac{161.6}{984.3} & \frac{19^{5}}{\overline{1154.1}} & \frac{49^{s}}{863} & \frac{22}{1142} \\ \frac{22}{1006.3} & \frac{22}{1176.1} & \frac{45}{908} & \frac{58}{1200}\end{array}$

811

770

852

852

$\begin{array}{llll}1.21 & 1.50 & 1.01 & 1.34 \\ 1.24 & 1.53 & 1.07 & 1.41\end{array}$

$\begin{array}{llll}173.3 & 384.1 & 11 & 290\end{array}$

$\begin{array}{llll}195.3 & 406.1 & 56 & 348\end{array}$ 
Table $V$ LMFBR CAPITAL COST EVALUATION BY CONCEPT COST ANALYSIS ACCOUNT STRUCTURE (continued)

Notes and Adjustments:

a. Possibly included in Data Set $A$ BOP cost, but an additional $\$ 10 M$ adjustment assumed.

b. Apparently omitted, an additional $\$ 10 M$ assumed.

c. Accounts $21,23,24$ and 25 assumed completely covered by Data Set A BOP cost.

d. Not specifically noted elsewhere and assumed omitted; an adjustment ranging from $\$ 8 M$ to $\$ 10 M$ is assumed for Data Set $C$.

e. Steam generator building(s) included here.

f. This subaccount not considered strictly applicable for use of cooling towers, costs associated with this item are assumed to be covered by subaccounts 218 or 232.

g. Function covered in reactor auxiliary building, cost assumed covered in subaccount 215.

h. Function covered in reactor and auxiliary building.

i. A separate fuel handling building is assumed present, an adjustment of $\$ 4 M$ to $\$ 6 M$ is assumed for Data Set C.

j. Separate diesel-generator and control buildings are assumed present, an adjustment of $\$ 8 M$ to $\$ 10 M$ is assumed for Data Set $C$.

k. Total for subaccounts 221 and 222 , some costs may also be covered in subaccount 226.

1. Additional costs are expected associated with this category, but are considered to be covered by subaccount 226 .

m. Although not specifically noted to be included elsewhere, costs for this subaccount are assumed to be covered by subaccount 226 .

$n$. This category is not specifically noted to be included elsewhere and even though subaccount 226 is considered possibly sufficient to cover appropriate costs, an adjustment appears appropriate. Adjustments of $\$ 12 M, \$ 12 M, \$ 12 M$, and $\$ 15 M$ are assumed for Data Sets $A, B, C 1$ and $C 2$, respectively.

o. Specific costs for this category are not noted to be covered elsewhere, although this is quite likely. However, an adjustment of about $1.5 \%$ of the unadjusted total is assumed to be appropriate. This yields adjustments of $\$ 13 \mathrm{M}$ for $\mathrm{C} 1$ and $\$ 17 \mathrm{M}$ for $\mathrm{C2}$. 
Table $V$ LMFBR CAPITAL COST EVALUATION BY CONCEPT COST ANALYSIS ACCOUNT STRUCTURE (continued)

p. The total costs for accounts 91,92 and 93 are assumed to be included within the value indicated for account 91.

q. Considering the magnitude of other noted indirect costs, this subaccount is assumed to be covered.

$r$. Contingencies have been assumed to be included in basic estimates.

s. BOP contingency only, other has been assumed to be included in basic estimates.

t. Based on $\$ 770 / \mathrm{kW}(1 / 77)$ direct plus indirect costs for a $900 \mathrm{MW}(\mathrm{e})$ net LWR plant; Cost multiplier for scaling to $1978 \$$ is assumed to be 1.05; scaling for capacity is assumed to be by $\left(P_{1} / P_{2}\right)^{0.5}$. 


\section{CONCLUDING REMARKS}

Based on the review of the LMFBR capital cost estimates presented in the preceding pages, we conclude that all items with major cost impact have been included. Although some specific elements that provide important plant functions may have been omitted, the significance of the items to the total LMFBR cap'ital cost appears small. Consequently, comparison to LWR capital costs would be expected to be reasonable.

Review of the comparative data shows that the LMFBR costs would appear to range from costs comparable to the LWR to costs about 50 percent higher. However, LMFBR capital costs comparable to LWR costs do not appear realistic based on the engineering assessment of Section III. Examination of Data Set C1 shows that the closeness of the LMFBR estimate to the LWR value is due to a low balance-of-plant cost. The BOP costs for the LMFBR couTd possibly be comparable to BOP costs in the LWR, but significantly higher NSSS costs are expected for the LMFBR: consequentiy, total cost would not be expected to be comparable. It was noted that Data Set $\mathrm{C} 1$ gave the low values of a range and is, indeed, considered to be low. The remaining data sets appear to be reasonably credible and consistent with the design differences. The high indirect costs of Data Set $B$ are worthy of note, and are perhaps the most realistic values given for a fifth-of-a-kind LMFBR.

Capital cost estimates have previousiy been made for commercial power plants at various stages of development, and studies $(7,9,10)$ of LWR costs have shown significant variations - not all of which have been fully explained. The LMFBR estimates discussed here are considered to be no more or no less sound than other estimates made at comparable stages of development. Though the LWR is considered commercially developed, there remains enough variation in its costs to add yet another element of uncertainty to relative-cost evaluations of the LMFBR. 
1. "CONCEPT-A Computer Code for Conceptual Cost Estimates of SteamElectric Power Plants," ERDA-108, U.S. Energy Research and Development Administration, June 1975.

2. "Technical Comparison of Prototype Large Breeder Reactor (PLBR) Phase II Competing Designs," Final Report under Contract No. 31-109-38-3547, United Engineers \& Constructors, Inc., January 1978.

3. Reference Safety Analysis Report, RESAR-414, Westinghouse Nuclear Energy Systems, NRC Docket No. 50-572, December 30, 1976 and subsequent amendments.

4. Black Fox Station, Units One and Two, Preliminary Safety Analysis Report, Public Service of Oklahoma, NRC Docket No. 50-556, December 22, 1975 and subsequent amendments.

5. William E. Mooz, The Rand Corporation, Letter to Kenneth D. Kirby, Southern Science Applications, Inc., September 28, 1978.

6. "Guide for Economic Evaluation of Nuclear Reactor Plant Designs," NUS-531, NUS Corporation, January 1969.

7. "Capital Cost: Pressurized Water Reactor Plant," NUREG-0241, United Engineers \& Constructors, Inc., June 1977.

8. William E. Mooz, The Rand Corporation, Private Communication, October $6,1978$.

9. William E. Mooz, "Cost Analysis of Light Water Reactor Power Plants," R-2304-DOE, The Rand Corporation, June 1978.

10. "Power Plant Capital Costs, Current Trends and Sensitivity to Economic Parameters," WASH-1345, United States Atomic Energy Commission, October 1974. 
RAND/R-2441-ACDA 
